Supporting Information

\title{
Holey Pt Nanosheets on NiFe-Hydroxide Laminates: Synergistically Enhanced Electrocatalytic 2D-Interface toward Hydrogen Evolution Reaction
}

Sun Woo Jang, ${ }^{\dagger \Delta}$ Soumen Dutta,${ }^{\dagger \Delta}$ Amit Kumar, ${ }^{\dagger \ddagger}$ Yu-Rim Hong,,${ }^{\dagger}$ Hanuel Kang,

Shinbi Lee ${ }^{\S}$ Sunmin Ryu,${ }^{\ddagger}$ Wonyong Choi,${ }^{\S}$ In Su Lee ${ }^{* \dagger \ddagger}$

${ }^{\dagger}$ Creative Research Initiative Center for Nanospace-confined Chemical Reactions

(NCCR) Pohang University of Science and Technology (POSTECH), Pohang 37673

(Korea)

${ }^{\ddagger}$ Department of Chemistry, Pohang University of Science and Technology (POSTECH),

Pohang 37673 (Korea)

${ }^{\S}$ Division of Environmental Science and Engineering, Pohang University of Science and Technology (POSTECH), Pohang 37673 (Korea)

${ }^{\Delta}$ These authors contributed equally to this work.

"Correspondence: insulee97@ postech.ac.kr (I. S. L.) 


\section{Table of Contents for the Supporting Information}

Methods 2

Figure S1. TEM images of LDH template and formed 2D-Pt on LDH....................................10

Figure S2. ICP-AES analyses during A-LDH/2D-Pt formation.............................................

Figure S3. HRTEM image of 2D-Pt highlighting some of the ordered domains.............. 12

Figure S4. XPS analyses for various intermediates of A-LDH/2D-Pt...................................13

Figure S5. TEM analyses for various intermediates of A-LDH/2D-Pt ......................14

Figure S6.TEM images of Pt through seed-mediated growth................................15

Figure S7. TEM images of Pt grown using other templates............................ 17

Figure S8. TEM images of 2D-Pt using varied Pt-precursor amount...................... 18

Figure S9. TEM images of 2D-Pt using varied ascorbic acid amount.....................................19

Figure S10. TEM images of 2D-Pt under varied reaction temperatures.....................20

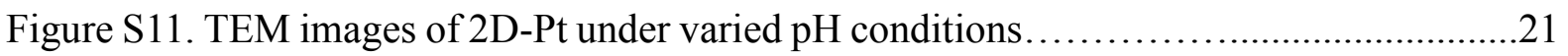

Figure S12. TEM images of 2D-Pt grown on other LDHs............................... 22

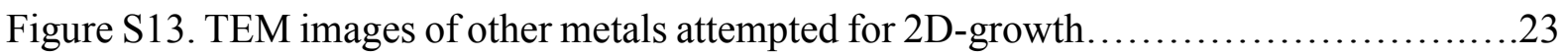

Figure S14. Attempt to control the pore size of 2D-Pt..................................24

Figure S15. TEM analyses for various intermediates of N-LDH/2D-Pt.....................25

Figure S16. Stability of N-LDH/2D-Pt under varied conditions............................................26

Figure S17.LSV and EIS plots for various HER electrocatalysts..........................27

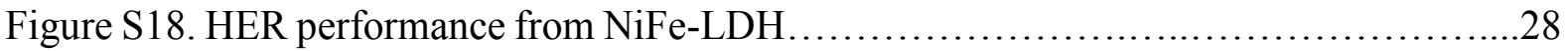

Figure S19. Mass and specific activity plots for various catalysts..................................29

Figure S20. HER performance: N-LDH/2D-Pt vs 10\% Pt/C...............................

Figure S21. Plots for electrochemical surface area (ECSA) calculation..................... 31

Figure S22. Reproducibility test for electrochemical HER by N-LDH/2D-Pt.................32

Figure S23. HER performance of N-LDH/2D-Pt with lower Pt loading on GCE.............33

Figure S24. Hydrogen gas measurement by GC and FE calculation.........................34

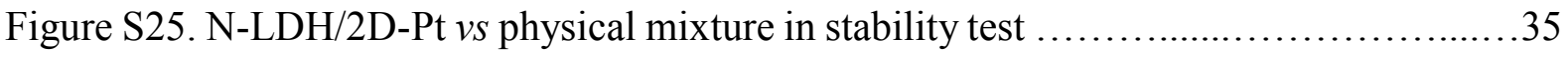

Figure S26. Stability test of A-LDH/2D-Pt and 2D-Pt.............................. 36

Figure S27. HER performance: N-LDH/2D-Pt $v s$ Pt black ............................ 37

Figure S28. TEM images for Post-HER N-LDH/2D-Pt sample........................... 38

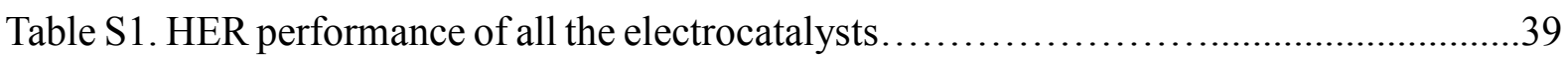

Table S2. Mass and specific activities of all the electrocatalysts.........................................40

Table S3. Mass activity for various tested catalysts............................................. 41

Table S4. Summery for EIS results for various electrocatalysts.............................42

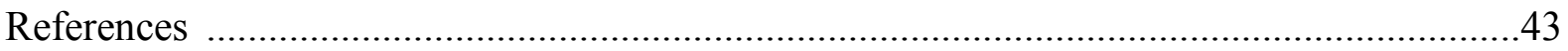




\section{METHODS}

\section{General Consideration}

Reagents and materials. All reagents, including nickel(II) nitrate hexahydrate (Strem), iron(III) nitrate nonahydrate (Acros organics), sodium hydroxide (Samchun Chem.), sodium tetrachloroplatinate(II) hydrate (Strem), L(+)-ascorbic acid (Samcun Chem.), ethanol (Samchun chem.), 20\% Pt/C (Aldrich), 10\% Pt/C (Aldrich), platinum black (Aldrich), carbon black (Vulcan XC 72R), hydrochloric acid (Samchun Chem.), graphene oxide (Aldrich), sodium tetrachloropalladate(II) trihydrate (Strem), iridium(III) chloride hydrate (Strem), ruthenium(III) chloride hydrate (Strem), hydrogentetrachloroaurate(III) hydrate (Strem), aluminum(III) nitrate nonahydrate (JUNSEI), aluminum(III) chloride hexahydrate (Kanto Chem.) and magnesium(II) chloride hexahydrate (Aldrich), were used as purchased without any further purification.

Instruments and characterization. TEM and HRTEM analyses were conducted with a JEOL JEM-2100 and JEM-2200FS with Image Cs-corrector at $200 \mathrm{kV}$. Scanning transmission electron microscope and energy-dispersive X-ray spectrometry (STEM-EDS) elemental mapping were performed with JEOL JEM-2100F at $200 \mathrm{kV}$. Scanning electron microscopy (SEM) was carried out at $2 \mathrm{kV}$ with JSM 7800F Prime (JEOL) instrument. XRD patterns were obtained using a D/MAX-2500/PC (18 kW) (Rigaku) with a scan rate of $3^{\circ} \mathrm{min}^{-1}$. The oxidation state of the elemnts was determined by XPS analyses with an X-ray source of monochromated Al Ka (1486.6 eV) using a theta probe AR-XPS System (Thermo Fisher, U.K.). Topographical information of all of synthesized samples was revealed with an atomic force microscope (AFM; Bruker, VEECO-3100). The height-profile of the AFM images were obtained in a non-contact mode using $\mathrm{Si}-\mathrm{N}$ tips with a nominal tip radium of $<10 \mathrm{~nm}$. (ACT Part). Elemental quantity was analyzed by inductively coupled plasma atomic emission spectrometry (ICP-AES) using iCAP 7400 (Thermo Scientific ${ }^{\mathrm{TM}}$ ).

Sample preparation for TEM, HRTEM and STEM-EDS. First, a suspension of the assynthesized materials dispersed in ethanol $\left(0.5 \mathrm{mg} \mathrm{mL}^{-1}\right)$ were prepared, and then a couple of drops of each colloidal suspension were dropped on $\mathrm{Cu}$ TEM grid followed by drying in an airoven at $70{ }^{\circ} \mathrm{C}$ before conducting the analyses.

Sample preparation for AFM, SEM and XPS. Here, $\mathrm{SiO}_{2}$ wafer (thickness $=525 \mu \mathrm{m}$ ) was used as substrate for AFM, SEM and XPS studies. $\mathrm{SiO}_{2}$ wafer was cut into $1 \mathrm{~cm} \times 1 \mathrm{~cm}$ followed by cleaning using acetone through sonication for $30 \mathrm{~min}$. Then, ethanolic dispersion 
of the samples $\left(0.1 \mathrm{mg} \mathrm{mL}^{-1}\right)$ were used to coat the substrate by using spin-coater under ambient condition.

Sample preparation for XRD. The air-dried powdered samples were grinded using pestle and mortar, and then recorded the XRD pattern.

Sample preparation for ICP-AES analyses. A certain amount of powdered samples were treated with aqua-regia (mixture of $\mathrm{HNO}_{3}$ and $\mathrm{HCl}$ in 1:3 vol. ratio) for overnight under room temperature. Then the solution was filtered through membrane filter (DISMIC-25 CS, pore size $=0.20 \mu \mathrm{m})$, and the filtrate was utilized for ICP-AES analyses.

\section{Synthesis of 2D-Pt with Various LDH Templates}

Synthesis of NiFe-LDH. Preparation of NiFe-LDH was carried out by following a reported protocol. ${ }^{1}$ Typically, $10.0 \mathrm{~mL}$ of aqueous solution containing $2.4 \mathrm{mmol} \mathrm{Ni}\left(\mathrm{NO}_{3}\right)_{2} \cdot 6 \mathrm{H}_{2} \mathrm{O}$ $(\sim 0.698 \mathrm{~g})$ and $0.8 \mathrm{mmol} \mathrm{Fe}\left(\mathrm{NO}_{3}\right)_{3} \cdot 6 \mathrm{H}_{2} \mathrm{O}(\sim 0.230 \mathrm{~g})$ was mixed with $40.0 \mathrm{~mL}$ alkaline aqueous solution containing $7.2 \mathrm{mmol}$ of $\mathrm{NaOH}(\sim 0.288 \mathrm{~g})$ and the mixture solution was continuously stirred for next $10 \mathrm{~min}$. The resulting suspension was centrifuged at $12000 \mathrm{rpm}$ for $15 \mathrm{~min}$, and washed twice with deionized water (DI) to remove the excess free metal salts and subsequently dispersed in $40.0 \mathrm{~mL}$ of deionized water. Then the final aqueous suspension was transferred into Teflon-lined stainless-steel autoclave and subsequently placed in a preheated oven for hydrothermal treatment at $150{ }^{\circ} \mathrm{C}$ for $12 \mathrm{~h}$. The $\mathrm{LDH}$ products were collected by centrifuge, and then repeatedly washed with deionized water and ethanol.

Synthesis of NiAl-LDH. In a synthetic process, $3.5 \mathrm{mmol}$ of $\mathrm{Al}\left(\mathrm{NO}_{3}\right)_{3} \cdot 9 \mathrm{H}_{2} \mathrm{O}(\sim 1.313 \mathrm{~g})$ and $7.0 \mathrm{mmol}$ of $\mathrm{Ni}\left(\mathrm{NO}_{3}\right)_{2} \cdot 6 \mathrm{H}_{2} \mathrm{O}(\sim 2.036 \mathrm{~g})$ were mixed to $35.0 \mathrm{~mL}$ of deionized water under magnetic stirring for $15 \mathrm{~min}$ at room temperature. After that, $15.0 \mathrm{mmol}$ of urea $(\sim 0.901 \mathrm{~g})$ was added slowly with continuous stirring for $15 \mathrm{~min}$. Then the final aqueous suspension was transferred into Teflon-lined stainless-steel autoclave and placed in a preheated oven for hydrothermal treatment at $180{ }^{\circ} \mathrm{C}$ for $12 \mathrm{~h}$. Finally, the products were collected by centrifuge, repeatedly washed with deionized water and ethanol.

Synthesis of MgAl-LDH. Typically, $10.0 \mathrm{~mL}$ of aqueous solution containing $1.0 \mathrm{mmol}$ of $\mathrm{AlCl}_{3} \cdot 6 \mathrm{H}_{2} \mathrm{O}(\sim 0.241 \mathrm{~g})$ and $3.0 \mathrm{mmol}$ of $\mathrm{MgCl}_{2} \cdot 6 \mathrm{H}_{2} \mathrm{O}(\sim 0.610 \mathrm{~g})$ was mixed with $20.0 \mathrm{~mL}$ alkaline solution containing $8.0 \mathrm{mmol}$ of $\mathrm{NaOH}(\sim 0.320 \mathrm{~g})$ with vigorous stirring. Then the solution was thermally treated under refluxing condition for $2 \mathrm{~h}$. Finally, the products were collected by centrifuge, and washed thoroughly. 
2D-Pt growth on NiAl-LDH or MgAl-LDH. 2D-Pt growth was attempted by applying the same procedure of synthesizing A-LDH/2D-Pt, except for the use of NiAl-LDH or MgAlLDH template instead of NiFe-LDH.

\section{Time Course Study during 2D-Pt Growth}

TEM analysis with various intermediates. To investigate the formation mechanism for 2D-Pt under acidic medium, a reaction setup for A-LDH/2D-Pt was performed for time-course TEM analyses. Typically, $0.5 \mathrm{~mL}$ aqueous suspension of pre-synthesized NiFe-LDH $\left(10 \mathrm{mg} \mathrm{mL}^{-1}\right)$ was mixed with $0.5 \mathrm{~mL}$ freshly prepared platinum precursor solution $\left(\mathrm{Na}_{2} \mathrm{PtCl}_{4} \cdot \mathrm{xH}_{2} \mathrm{O} ; 100\right.$ $\mathrm{mM}$ ), and the reaction mixture was allowed to stirred for $30 \mathrm{~min}$ at room temperature. Next, $1.5 \mathrm{~mL}$ ascorbic acid solution (AA; $33.3 \mathrm{mM}$ ) was quickly added at room temperature into the above solution, and a small aliquot $(\sim 50 \mu \mathrm{L})$ from the resultant mixture was withdrawn for TEM analysis. Afterwards, the whole reaction mixture was kept on a preheated oil bath $\left(70{ }^{\circ} \mathrm{C}\right.$, $10 \mathrm{~min}$ ) under stirring condition. Now, during the progression of 2D-Pt growth under heating condition, a number of reaction intermediates $(\sim 100-125 \mu \mathrm{L}$ dispersion $)$ at different time intervals were isolated from the reaction mixture, which were washed properly and then analyzed by TEM. Similarly, time-course TEM analyses were carried out for various intermediates prepared during the evolution of N-LDH/2D-Pt i.e., product obtained from neutral medium.

ICP-AES analyses during the synthesis of $A-L D H / 2 D-P t$. In order to investigate the possible dissolution of $\mathrm{Ni}$ and $\mathrm{Fe}$ during growth of 2D-Pt under acidic condition, ICP-AES measurement was carried out from the products obtained from a reaction mixture after scaling up of all the precursors for A-LDH/2D-Pt. Here the real amount of Ni, Fe and Pt was estimated in the synthesized product or intermediates. In a standard procedure, $3.5 \mathrm{~mL}$ of presynthesized $\mathrm{NiFe}-\mathrm{LDH}$ dispersion $\left(10 \mathrm{mg} \mathrm{mL}^{-1}\right)$ was first mixed with $3.5 \mathrm{~mL}$ freshly prepared Pt-precursor solutions $(100 \mathrm{mM})$ and stirred for $30 \mathrm{~min}$ at room temperature, forming [ $\left.\mathrm{LDH}+\mathrm{Pt}^{2+}\right]$. Next, $10.5 \mathrm{~mL}$ of ascorbic acid solution (AA; $33.3 \mathrm{mM}$ ) was added into the above solution at room temperature, and then the whole reaction mixture, designated as $\left[\mathrm{LDH}+\mathrm{Pt}^{2+}+\mathrm{AA}\right]$, was placed in the preheated oil bath at $70{ }^{\circ} \mathrm{C}$ under magnetic stirring. During the evolution of 2D-Pt, from the well-dispersed solution, a reaction mixture corresponding to $5 \mathrm{mg}$ of NiFe-LDH (i.e., 2.5 $\mathrm{mL}$ of reaction mixture) was extracted each time. In addition to the intermediates obtained during heat treatment, various materials such as $\left[\mathrm{LDH}+\mathrm{Pt}^{2+}\right]$ and $\left[\mathrm{LDH}+\mathrm{Pt}^{2+}+\mathrm{AA}\right]$ mixture 
were also isolated, properly washed and dried before treating them with aqua-regia (mixture of $\mathrm{HNO}_{3}$ and $\mathrm{HCl}$ in 1:3 vol. ratio) in order to prepare the solutions for ICP-AES analyses.

Pt 4 XPS analyses during the synthesis of A-LDH/2D-Pt. Here the procedure was followed similar to above indicated one, and the analyzed materials were $\left[\mathrm{LDH}+\mathrm{Pt}^{2+}\right],\left[\mathrm{LDH}+\mathrm{Pt}^{2+}+\right.$ AA] and finally the product obtained after $5 \mathrm{~min}$ of heating at $70^{\circ} \mathrm{C}$. All the isolated materials were properly washed, and then dried before sent for XPS analyses.

\section{Attempt for Pt Growth with Pre-formed Seed on LDH}

Preparation of seeds on LDH surface. First, $\mathrm{Pt}$ precursors were allowed to form $\mathrm{Pt}^{2+}$-clusters bound to LDH surface, and then the solid material ( $\mathrm{Pt}^{2+}$-clusters bound $\mathrm{LDH}$ ) was isolated from the solution to remove the excess ions before treating in presence of reducing agent for the formation of $\mathrm{Pt}^{0}$ seed particles attached to $\mathrm{LDH}$ surface. In a typical procedure, $5.0 \mathrm{mg}$ of presynthesized NiFe-LDH was dissolved in $0.5 \mathrm{~mL}$ of deionized water, followed by addition of a $0.5 \mathrm{~mL} \mathrm{Na} 2 \mathrm{PtCl}_{4} \cdot \mathrm{xH}_{2} \mathrm{O}(70 \mathrm{mM})$ was carried out under magnetic stirring for $30 \mathrm{~min}$ at room temperature. Then, $1.5 \mathrm{~mL}$ reducing agent containing $3.0 \mathrm{mg}$ of ascorbic acid $(\sim 0.017$ mmol) was added into the mixed solution, and stirred for $1 \mathrm{~min}$ at the same temperature. Followed by quick centrifugation, the resultant material was collected, which further treated with fresh ascorbic acid solution (3.0 mg dissolved in $1.5 \mathrm{~mL} \mathrm{DI}$ ), and then heat treatment was performed with the whole reaction mixture for $1 \mathrm{~h}$ at $60{ }^{\circ} \mathrm{C}$ using a preheated oil bath. Finally, the resultant material was collected from the solution, washed by water, and then dispersed in DI water for further use. Thus, 3 5 nm-sized $\mathrm{Pt}^{0}$ seeds were generated on NiFe-LDH.

Attempt for Pt growth. In order to perform seed-mediated growth of Pt, $5.0 \mathrm{mg}$ of the assynthesized $\mathrm{NiFe}-\mathrm{LDH} / \mathrm{Pt}^{0}$ seed dispersed in $0.5 \mathrm{~mL}$ deionized water was first mixed with 0.5 $\mathrm{mL}$ freshly prepared platinum precursor solution $\left(\mathrm{Na}_{2} \mathrm{PtCl}_{4} \cdot \mathrm{xH}_{2} \mathrm{O} ; 100 \mathrm{mM}\right)$ and stirred for $30 \mathrm{~min}$ at room temperature. Then, $1.5 \mathrm{~mL}$ ascorbic acid solution (AA; $33.3 \mathrm{mM}$ ) was added into the above solution at room temperature, before heating on a preheated oil bath $\left(70{ }^{\circ} \mathrm{C}\right)$ under stirring for $10 \mathrm{~min}$. Finally, the resulting material was isolated from the reaction solution though centrifugation, washed with ethanol for three times, and analyzed by TEM.

5. Attempt to Grow 2D-Pt on Other Substrates. To test the effect of substrate for 2D-Pt growth, GO and graphene were bought, whereas other substrates were synthesized. Three 
dimensional (3D)-silica nanospheres were prepared following our reported article, ${ }^{2}$ while 2Dporous metal oxide i.e., $p$-2D-NiFe oxide was synthesized by applying our laboratory developed protocol to prepare porous metal oxides from metal hydroxide layers. ${ }^{3}$ In case of 2D-Ni MOF, the substrate was synthesized following a reported process. ${ }^{4}$

Here, the synthetic processes using other substrates to grow Pt were followed as same as ALDH/2D-Pt, where different substrates $(\sim 5 \mathrm{mg})$ under well-dispersed condition in deionized water $(0.5 \mathrm{~mL})$ were employed instead of two-dimensional NiFe-LDH as substrate keeping other reaction parameters unchanged.

In absence of any templates, $0.5 \mathrm{~mL}$ platinum precursor $\left(\mathrm{Na}_{2} \mathrm{PtCl}_{4} \cdot \mathrm{xH}_{2} \mathrm{O} ; 100 \mathrm{mM}\right)$ was directly added to $1.5 \mathrm{~mL}$ ascorbic acid solution (AA; $33.3 \mathrm{mM}$ ) at room temperature, and then the whole reaction mixture was heated in oil-bath at $70{ }^{\circ} \mathrm{C}$ for 10 min under magnetic stirring.

\section{2D-Pt Growth on NiFe-LDH under Various Synthetic Conditions.}

Pt amount variation. Here the synthetic process is exactly same like A-LDH/2D-Pt with only difference in varying Pt-precursor concentration such as 65.0, 80.0, 100.0, 125.0 and 150.0 $\mathrm{mM}$ of the added $\mathrm{Pt}^{2+}$-solution $(0.5 \mathrm{~mL}$ each) into the well-dispersed $\mathrm{NiFe}-\mathrm{LDH}$ solution $(0.5$ $\mathrm{mL} ; 10 \mathrm{mg} \mathrm{mL}^{-1}$ ) under magnetic stirring for $30 \mathrm{~min}$ at room temperature. Then, addition of ascorbic acid $(1.5 \mathrm{~mL} ; 33.3 \mathrm{mM})$ at room temperature followed by heat treatment of the whole reaction mixture on a preheated oil bath $\left(70^{\circ} \mathrm{C}\right)$ for $10 \mathrm{~min}$ was performed for each cases. Finally, the resulting materials were collected by centrifugation, followed by washing with ethanol for three times, and then analyzed by TEM.

Ascorbic acid (AA) amount variation. Here, the synthetic procedure is similar like ALDH/2D-Pt, but the variation in AA amount was carried out with keeping all the parameters unchanged. The added concentration of AA are ranged from 11.2-44.5 mM (1.5 mL) into the well-mixed solution of NiFe-LDH and Pt-precursor. After the heat treatment at $70{ }^{\circ} \mathrm{C}$ for 10 min, all the resultant materials were isolated, and then washed properly before analyzed by TEM.

Temperature variation. The synthetic process was same as for A-LDH/2D-Pt with only difference in applied reaction temperature varied at 70,75 and $80{ }^{\circ} \mathrm{C}$. In all the cases, $0.5 \mathrm{~mL}$ of NiFe-LDH (10 mg mL $\left.{ }^{-1}\right), 0.5 \mathrm{~mL}$ of $\mathrm{Na}_{2} \mathrm{PtCl}_{4} \cdot \mathrm{xH}_{2} \mathrm{O}(100 \mathrm{mM})$, and $1.5 \mathrm{~mL}$ ascorbic acid solution $(33.3 \mathrm{mM})$ were used for the reaction under heating at various temperatures under 
stirring condition (10 min). Finally, the resultant materials were isolated individually, and then washed properly before analyzed by TEM.

pH variation. In this case, $\mathrm{pH}$ of the reaction mixture was varied while keeping other parameters to prepare A-LDH/2D-Pt unchanged. In a standard procedure, $0.5 \mathrm{~mL}$ of welldispersed NiFe-LDH (10 $\left.\mathrm{mg} \mathrm{mL}^{-1}\right)$ was stirred with aqueous Pt-precursor $(0.5 \mathrm{~mL} ; 100 \mathrm{mM})$ for $30 \mathrm{~min}$ at room temperature. Then, $1.5 \mathrm{~mL}$ ascorbic acid solution $(33.3 \mathrm{mM})$ was added into the above solution, followed by $\mathrm{pH}$ adjustment of the reaction mixture was carried out. Here, the adjusted $\mathrm{pH}$ were varied to $3.5,7.0,9.0$ and 11.0 by dropwise addition of $0.1 \mathrm{M}$ $\mathrm{NaOH}$. Next, the reaction mixtures were kept for heat treatment at $70{ }^{\circ} \mathrm{C}(10 \mathrm{~min})$ under magnetic stirring for 2D-Pt growth. Finally, the resultant materials were isolated from the reaction mixture through centrifugation, and then washed properly before analyzed by TEM.

7. Growth of Other Metals (Au, Pd, Ru, Ir) on LDH. For the growth of other metals, the same precursor amount $(\sim 0.05 \mathrm{mmol})$ of the respective metals was used as for A-LDH/2D-Pt case with keeping all other conditions unaltered. In detail, $0.5 \mathrm{~mL}$ of presynthesized NiFe-LDH dispersion $\left(10 \mathrm{mg} \mathrm{mL}^{-1}\right)$ was first mixed with $0.5 \mathrm{~mL}$ freshly prepared various metal precursor solutions $(100 \mathrm{mM})$ and stirred for $30 \mathrm{~min}$ at room temperature. Then, $1.5 \mathrm{~mL}$ ascorbic acid solution (AA; $33.3 \mathrm{mM}$ ) was added into the above solution at room temperature, before heating on a preheated oil bath $\left(70{ }^{\circ} \mathrm{C}\right)$ under stirring for $10 \mathrm{~min}$. Finally, the resulting materials were isolated from the reaction solutions though centrifugation, then washed with ethanol for three times, and stored in aqueous dispersion.

8. Electrocatalysis Study. The electrocatalytic studies were performed in Autolab PGSTAT302N potentiostat workstation using three-electrode configuration at ambient temperature. Before catalyst drop casting, glassy carbon rotating disk electrode (GC RDE, surface area $=0.07 \mathrm{~cm}^{2}$, Mehtrom) was thoroughly cleaned by polishing with $\mathrm{Al}_{2} \mathrm{O}_{3}$ powder and then ultrasonically washed with deionized water and absolute ethanol, and finally air-dried at room temperature. For N-LDH/2D-Pt, A-LDH/2D-Pt, 2D-Pt, 20\% Pt/C, 10\% Pt/C, Pt black samples, the catalysts were directly used to make $3 \mathrm{mg} \mathrm{mL}^{-1}$ catalyst ink before depositing on GCE. However, for physical mixture sample [LDH + 2D-Pt], a (1:1) weight ratio of NiFeLDH and 2D-Pt, and for (N-LDH/2D-Pt + carbon) sample, a (2:3) weight ratio of N-LDH/2D- 
Pt and carbon black, were first mixed thoroughly before preparing $3 \mathrm{mg} \mathrm{mL}^{-1}$ catalyst dispersion.

The polarization curves were recorded at a scan rate of $2 \mathrm{mV} \mathrm{s}^{-1}$ under a rotation rate of 1600 r.p.m, and $70 \% i R$-compensation was applied to correct the ohmic potential drop caused by the solution resistance $\left(\mathrm{R}_{\mathrm{s}}\right)$. The electrochemical impedance spectra (EIS) was recorded at $-0.1 \mathrm{~V}$ vs RHE in the frequency range of $0.01-100 \mathrm{kHz}$ for all the electrocatalysts. All potentials reported here were normalized with respect to the reversible hydrogen electrode (RHE) by adding a value of $(0.21+0.059 \times \mathrm{pH}) \mathrm{V}$.

For the $70 \% i R$-corrected graphs, the potential was corrected by following:

$\mathrm{V}_{i R \text {-corrected }}=\mathrm{V}_{\text {applied }}-$ current $\times \mathrm{R}_{\mathrm{s} .} \times 0.7$

For Tafel slope calculation, the $i R$-corrected LSV plots were used to follow $\eta=\mathrm{A} \times \log _{10}\left(I / I_{0}\right)$; where, $\eta=$ overpotential $(\mathrm{V}), I=$ current density $\left(\mathrm{mA} \mathrm{cm}^{-2}\right), I_{0}=$ exchange current density $(\mathrm{mA}$ $\left.\mathrm{cm}^{-2}\right)$ and $\mathrm{A}=$ Tafel slope $\left(\mathrm{mV} \mathrm{dec}{ }^{-1}\right)$.

Electrochemical surface area (ECSA) calculation. To estimate ECSA values of the materials, double-layered capacitance $\left(\mathrm{C}_{\mathrm{dl}}\right)$ was measured using a simple cyclic voltammetry method. Here, the potential window has been chosen to be outside the material's possible faradic region (0.80-0.91 V vs RHE) and CV were recorded at various scan rates ranging from $25-200 \mathrm{mV} \mathrm{s}^{-}$ ${ }^{1}$. The capacitive current density, $\Delta \mathrm{J} / 2$, was linearly related to scan rate $\left(\Delta \mathrm{J}=\mathrm{J}_{\text {anodic }}-\mathrm{J}_{\text {cathodic }}\right.$ at $0.861 \mathrm{~V})$ and the double layer capacitance $\left(\mathrm{C}_{\mathrm{dl}}\right)$ was calculated from the slopes of these straight lines. $\mathrm{C}_{\mathrm{dl}}$ was further converted into ECSA using the specific capacitance value $(\sim 0.03 \mathrm{mF})$ of a standard $1.0 \mathrm{~cm}^{2}$ surface ${ }^{5,6}$.

Stability tests. For cyclic stability tests, CV cycles were run in (-0.05 to $-0.01 \mathrm{~V}$ vs RHE) potential range for 5000 cycles and then, $i R$-corrected polarization curves for initial and after $\mathrm{CV}$ cycles were compared. To obtain the chronopotentiometry $(\mathrm{CP})$ curves, a potential vs time plot was recorded for the samples under constant current density of $10 \mathrm{~mA} \mathrm{~cm}{ }^{-2}$. Similarly for chronoamperometry (CA) test, a current density vs time plot was recorded under a constant potential (-0.05 V vs RHE).

$\mathrm{H}_{2}$ gas measurement and Faradaic efficiency $(\mathrm{FE})$ calculation for $\mathrm{N}-\mathrm{LDH} / 2 \mathrm{D}$-Pt during HER. For quantitative hydrogen gas measurement by N-LDH/2D-Pt, a fresh catalyst ink (3 $\left.\mathrm{mg} \mathrm{mL} \mathrm{m}^{-1}\right)$ was drop casted on a clean piece of carbon paper (CP; $\left.0.5 \times 1 \mathrm{~cm}^{2}\right)$, making catalyst loading of CP-loaded N-LDH/2D-Pt $=0.2 \mathrm{mg} \mathrm{cm}^{-2}$, followed by air drying under ambient 
condition. Then, HER study was performed by a computer-controlled potentiostat-galvanostat (Gamry Instruments Reference 600) that was connected to a three-electrode electrochemical Pyrex cell using the fabricated CP-loaded N-LDH/2D-Pt, a Pt coiled wire and $\mathrm{Ag} / \mathrm{AgCl}(\mathrm{KCl}$ saturated) electrodes as working, counter and reference electrodes, respectively. The electrocatalysis in a typical three-electrode system was measured with a two-compartment cell separated by a Nafion membrane (Nafion Membrane N117). The amount of generated $\mathrm{H}_{2}$ in the reactor headspace $(71 \mathrm{~mL})$ was analyzed using a gas chromatograph (GC, HP6890A) equipped with a thermal conductivity detector (TCD) and a $5 \AA$ molecular sieve column. Ultra high purity argon (Linde, 99.9995\%) was used as the carrier gas, and $100 \mu \mathrm{L}$ of gas samples were intermittently withdrawn from the electrochemical cell with a glass syringe (Hamilton 81030) for the hydrogen gas measurement. All cell compartments were thoroughly sealed with rubber septa to prevent any gas leakage. Prior to any measurement, the electrolyte was Arpurged for 15 min and the electrode was continuously held for HER at -0.06 V vs RHE.

For faradaic efficiency (FE) calculation for the materials:

$$
\mathrm{FE}=\eta=\frac{2 F n}{\int_{o n}^{o f f} I d t}
$$

where, $\eta=$ faradaic efficiency, $F=$ faradaic constant $\left(96485.332 \mathrm{C} \mathrm{mol}^{-1}\right), n=$ measured amount of hydrogen (mol) and $I=$ collected current $(\mathrm{mA})$. 

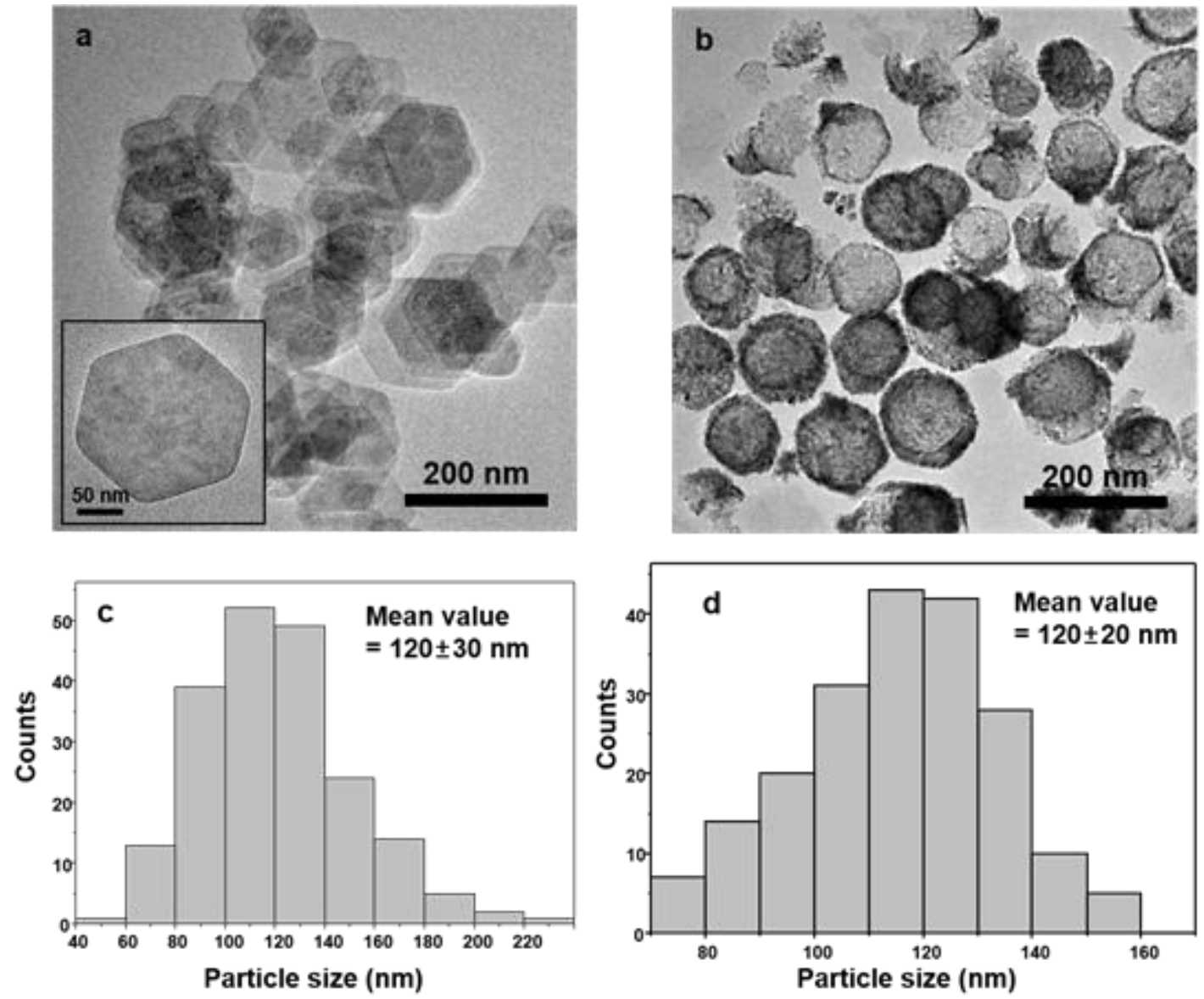

Figure S1. Morphological analyses of LDH template and formed 2D-Pt on LDH. Low magnification TEM images $(a, b)$ and size distribution $(c, d)$ for $(a, c)$ NiFe-LDH and $(b, d)$ ALDH/2D-Pt.

The average lateral size of NiFe-LDH before and after 2D-Pt grown is found to be same, which suggests 2D-Pt can be developed with the same size as its template LDH. 


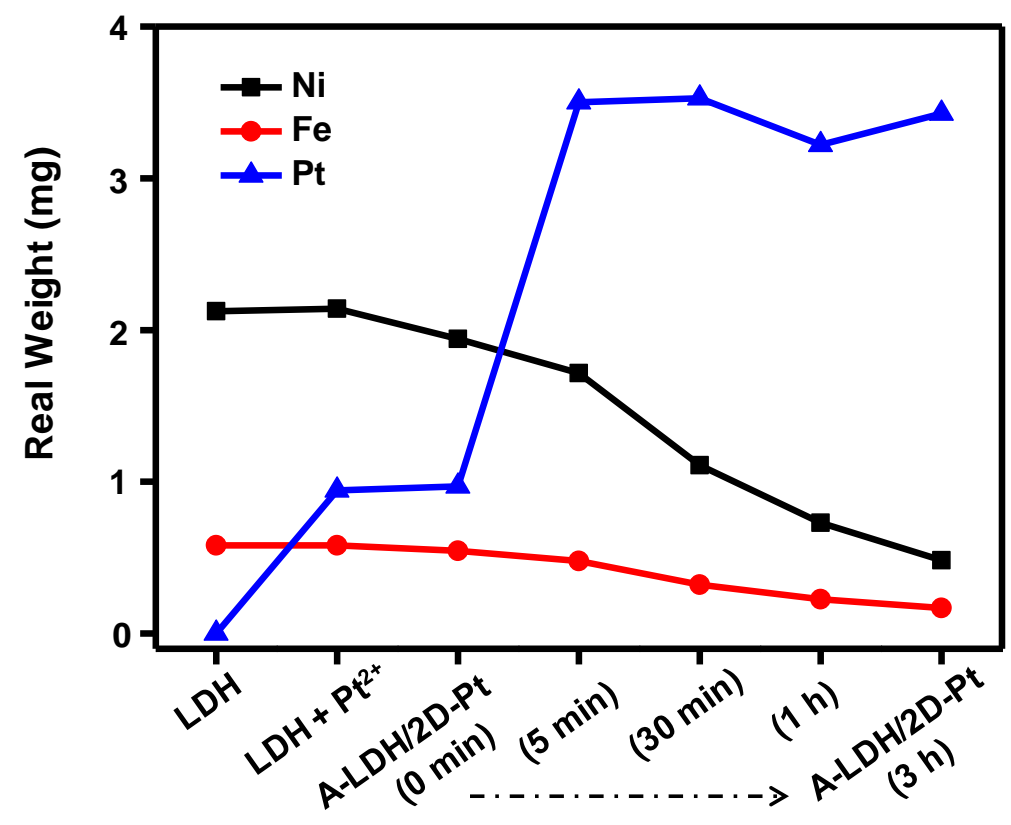

Products

Figure S2. ICP-AES analyses during A-LDH/2D-Pt formation.

Here the real weight of the metal ions has been analyzed in the formed intermediates/product after isolating them at various intervals. According to the resultant graph, Pt amount in the product increases sharply within $5 \mathrm{~min}$ of reaction, and then, no significant difference was found for Pt content, which indicates about the fast growth rate of 2D-Pt. On the other hand, the amount of $\mathrm{Ni}$ and Fe decreases gradually with time, as the LDH is expected to be dissolved with reaction progression due to the acidic conditions and high temperature employed for the synthetic process. Since, Pt amount remains unaltered after $5 \mathrm{~min}$, but Ni/Fe amount decreases with time, we fixed 10 minute of synthesis to keep LDH residual as high as possible without disturbing the full growth of 2D-Pt to obtain our targeted synergistic catalysis from the remaining $\mathrm{LDH}$ and the synthesized Pt.

Form the ICP-AES analyses, it is also noted that the $\mathrm{Ni} / \mathrm{Fe}$ atomic ratio in the $\mathrm{NiFe}-$ LDH is close to 3.4 . 


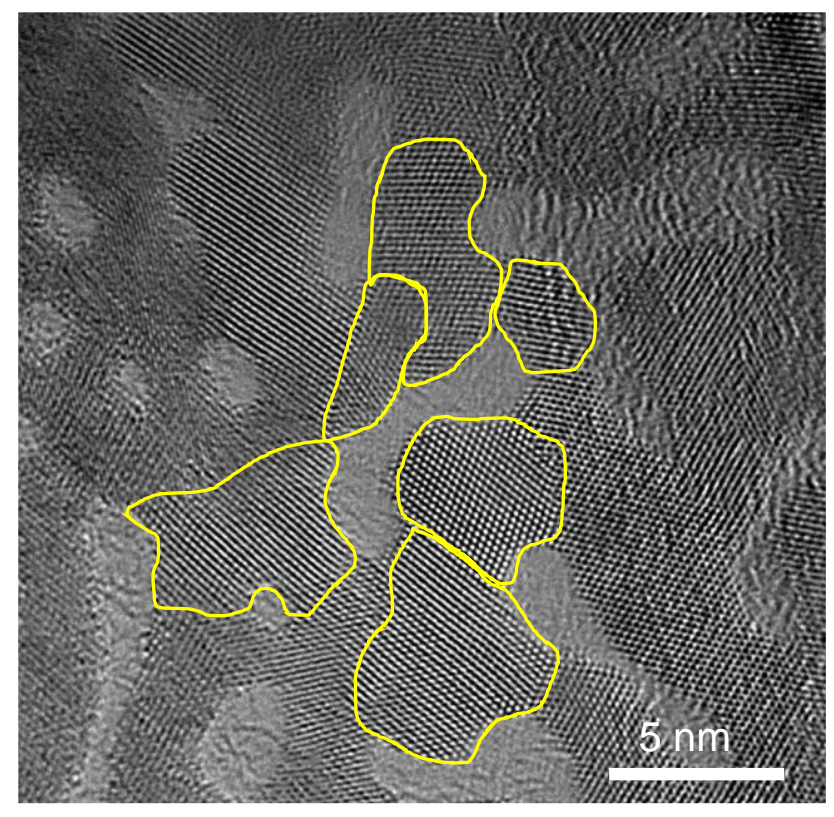

Figure S3. HRTEM image of 2D-Pt highlighting some of the ordered domains present in 2D-Pt.

According to HRTEM image, the average domain size is observed to be $\sim 5 \mathrm{~nm}$. Then domain size was further calculated from powder XRD pattern by using the following the Scherrer equation:

$$
\tau(\text { domain size })=\frac{K \cdot \lambda}{\beta \cdot \cos \theta}=\frac{0.9 \cdot 0.15406 \mathrm{~nm}}{1.172795 \cdot \frac{3.14}{180} \cdot \cos \left(\frac{39.9923}{2}\right)}=4.8949 \mathrm{~nm}
$$

Hence, the crystallite size estimated from powder XRD is well matched with the TEM analyses. 


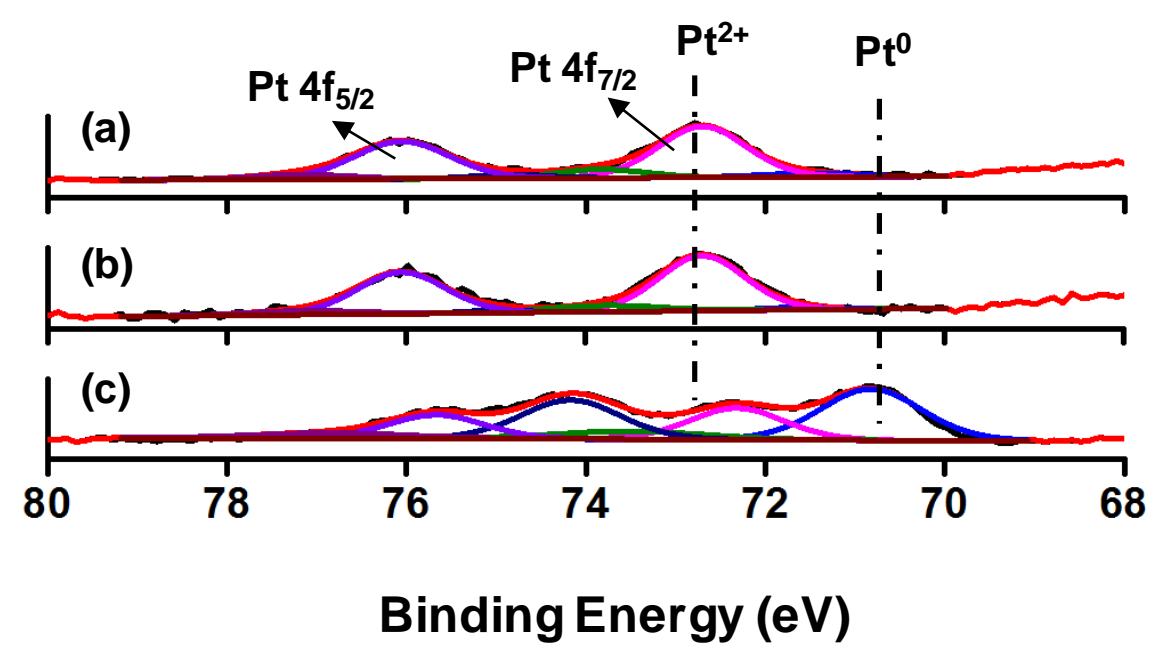

Figure S4. Pt 4f XPS analyses for various intermediates during A-LDH/2D-Pt formation. Pt 4f XPS spectra for various intermediates formed during the evolution of A-LDH/2D-Pt; (a) $\mathbf{L D H}+\mathbf{P t}^{2+}$ [product isolated just after the addition of Pt-precursor into the LDH dispersion], (b) $\mathbf{L D H}+\mathbf{P t}^{\mathbf{2}+}+\mathbf{A A}$ [product after AA was introduced into the solution containing LDH and $\mathrm{Pt}^{2+}$, but heat treatment was yet to start], (c) A-LDH/2D-Pt (5 min) [after 5 minutes of synthetic reaction].

The first product obtained after addition of $\mathrm{Pt}^{2+}$ precursor in $\mathrm{LDH}$ suspension only shows the presence of $\mathrm{Pt}^{2+}$ (Figure 4a), which does not even change with the addition of AA under room temperature (Figure $4 \mathrm{~b}$ ). After heating the reaction mixture, evolution of $\mathrm{Pt}^{0}$ is found along with some remaining $\mathrm{Pt}^{2+}$ species as described in Figure 4c. 

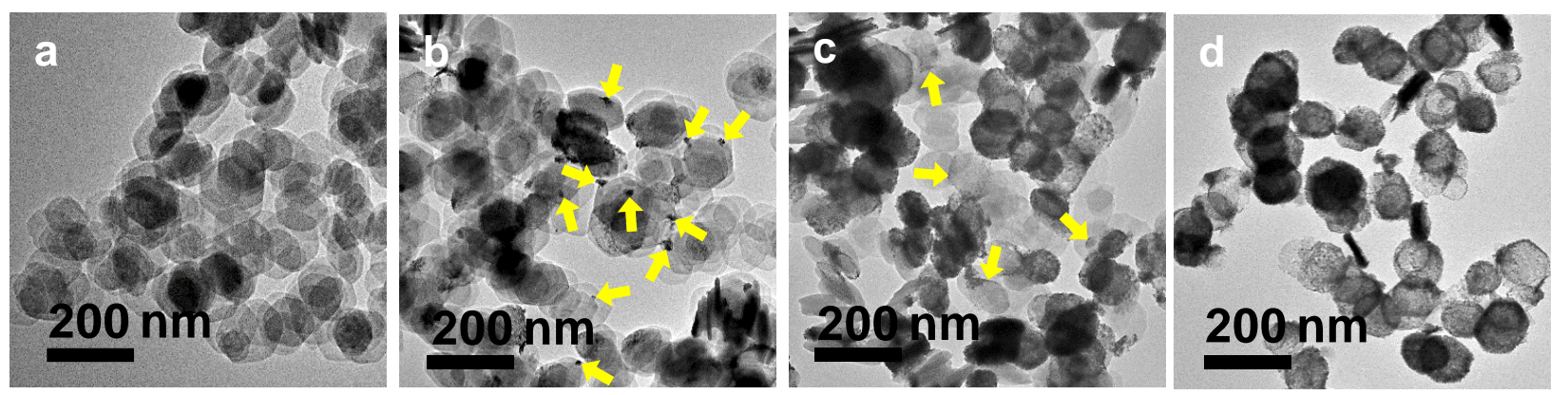

Figure S5. TEM analyses for various intermediates during A-LDH/2D-Pt formation. Low magnification TEM images for (a) $1^{\text {st }}$, (b) $2^{\text {nd }}$, (c) $3^{\text {rd }}$ intermediates, and (d) final product to confirm the growth mechanism of $2 \mathrm{D}-\mathrm{Pt}$ in acidic media. Here the $1^{\text {st }}$ intermediate corresponds to $\left[\mathrm{LDH}+\mathrm{Pt}^{2+}+\mathrm{AA}\right]$ mixture before heat treatment and the others obtained after heat-treatment of that mixture at various time intervals.

The arrows in panel (b) and (c) indicate the major product at the respective intermediates. In these two cases, some fully covered LDH layers were also observed. 

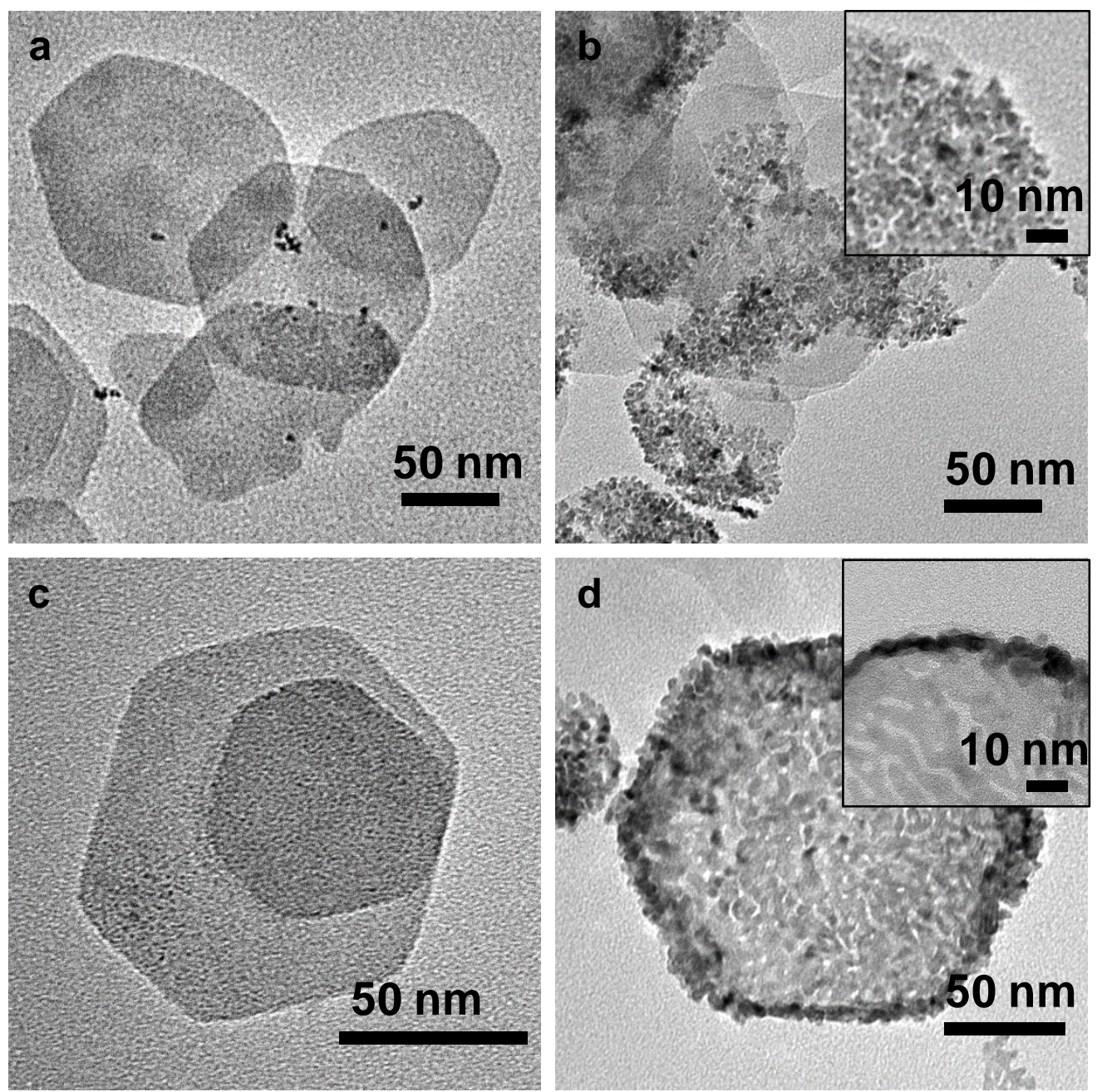

Figure S6. Seed-mediated growth vs our developed process for Pt growth on LDH. TEM images of Pt growth on NiFe-LDH using $(a, b)$ seed particles and $(c, d)$ without seed particle (i.e., A-LDH/2D-Pt). TEM image of (a) Pt seeds (size = 3-5 nm) on LDH and (b) evolved Pt on LDH after 10 minutes of reaction with fresh Pt precursor and ascorbic acid. TEM image of (c) first intermediate; possibly $\mathrm{Pt}^{2+}$-clusters (size: $\sim 1.0 \mathrm{~nm}$ ) on $\mathrm{LDH}$ and (d) the evolved $\mathrm{Pt}$ on LDH after 10 minutes of reaction in same growth solution containing Pt precursor and ascorbic acid for A-LDH/2D-Pt. Insets in panel (b) and (d) represent Pt's high magnification TEM image to differentiate the growth pattern of Pt. In all the cases for Pt growth, $0.5 \mathrm{~mL}$ of NiFeLDH or seed-loaded LDH (10 $\left.\mathrm{mg} \mathrm{mL}^{-1}\right), 0.5 \mathrm{~mL}$ of $\mathrm{Na}_{2} \mathrm{PtCl}_{4} \cdot \mathrm{xH}_{2} \mathrm{O}(100 \mathrm{mM})$, and $1.5 \mathrm{~mL}$ ascorbic acid solution $(33.3 \mathrm{mM})$ were used for the reaction at $70{ }^{\circ} \mathrm{C}$ for 10 min under stirring condition.

According to high magnification TEM analyses, in the $1^{\text {st }}$ case, the final product seems to be aggregated Pt particles forming 3D-bulk structures, whereas in the $2^{\text {nd }}$ case, the grown $\mathrm{Pt}$ is found to be two dimensional having smooth surface and numerous wavy pore channels. In both the cases, $\mathrm{LDH}$ were first allowed to form $\mathrm{Pt}^{2+}$-cluster bound to $\mathrm{LDH}$ surface. Then, in 
the first case, formation of $\mathrm{Pt}^{0}$-seeds $(3 \sim 5 \mathrm{~nm})$ is observed through chemical reduction of $\mathrm{Pt}^{2+}$ clusters by the added fresh batch of AA $\left(60{ }^{\circ} \mathrm{C}, 1 \mathrm{~h}\right)$. When these seed particles-loaded LDH was further introduced into a fresh growth solution $\left(70{ }^{\circ} \mathrm{C}, 10 \mathrm{~min}\right)$, formation of multiple nucleation sites and there relatively bigger size become key for forming 3D-aggregated $\mathrm{Pt}$ particles (inset; Figure 6b). On the other hand, in the $2^{\text {nd }}$ case i.e., A-LDH/2D-Pt, the generated small sized $\mathrm{Pt}^{2+}$-clusters (size: $\sim 1.0 \mathrm{~nm}$ ) bound to $2 \mathrm{D}$-LDH surface were kept in the same synthetic solution, which on experiencing with AA induced reduction don't converted into larger seed particles, rather a small-sized $\mathrm{Pt}^{0}$ seed on LDH surface is formed in-situ, and then one seed particle monitored the Pt-growth by consuming local $\mathrm{Pt}^{2+}$-clusters bound to $\mathrm{LDH}$ surface successively and continuously $\left(70{ }^{\circ} \mathrm{C}, 10 \mathrm{~min}\right)$ to form $2 \mathrm{D}-\mathrm{Pt}$. Thus, our developed process differs from seed-mediated growth of Pt. 

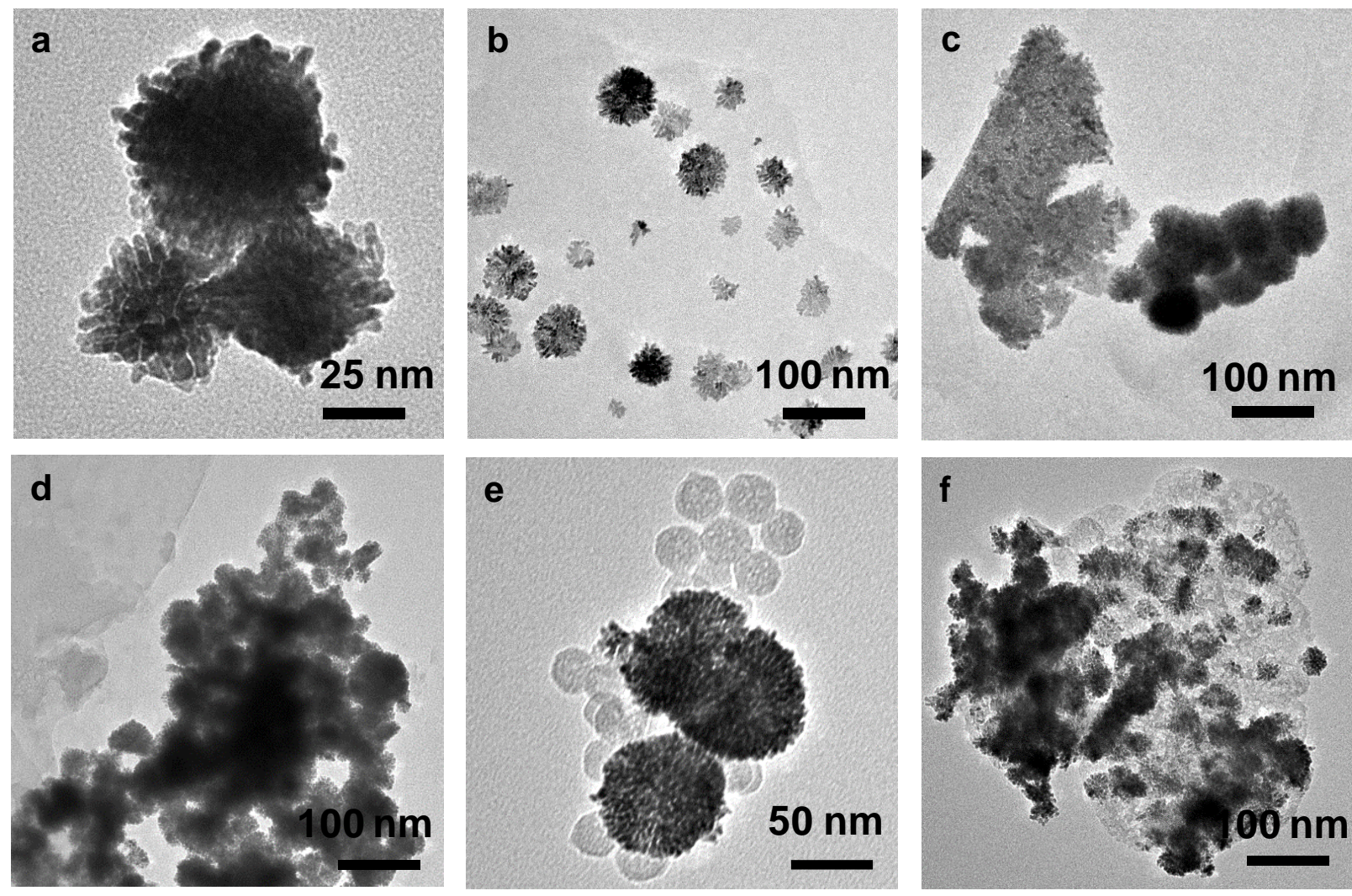

Figure S7. Pt growth using other substrates. TEM images of the grown Pt (a) without any template, and with using (b) graphene oxide (2D template), (c) graphene, (d) Ni-MOF (2D template), (e) $\mathrm{SiO}_{2}$ nanoparticles (3D template) and (f) $p$-2D-NiFe oxide (2D template) as template. In all the cases, $5.0 \mathrm{mg}$ of different substrates (dispersed in $0.5 \mathrm{~mL}$ DI water), 0.5 $\mathrm{mL}$ of $\mathrm{Na}_{2} \mathrm{PtCl}_{4} \cdot \mathrm{xH}_{2} \mathrm{O}(100 \mathrm{mM})$, and $1.5 \mathrm{~mL}$ ascorbic acid solution $(33.3 \mathrm{mM})$ were used for the reaction at $70{ }^{\circ} \mathrm{C}$ for 10 min under stirring condition.

Here, in absence of any templates the Pt growth was found to be 3D bulk structure. Among the various 2D templates, only graphene oxide is able to form somehow small-sized thin 2D-Pt, which possibly due to the supply of negatively charged functionalities in $2 \mathrm{D}$ template, suitable for crucial interaction with the Pt-precursor for 2D-Pt growth, as found by using LDH template. 

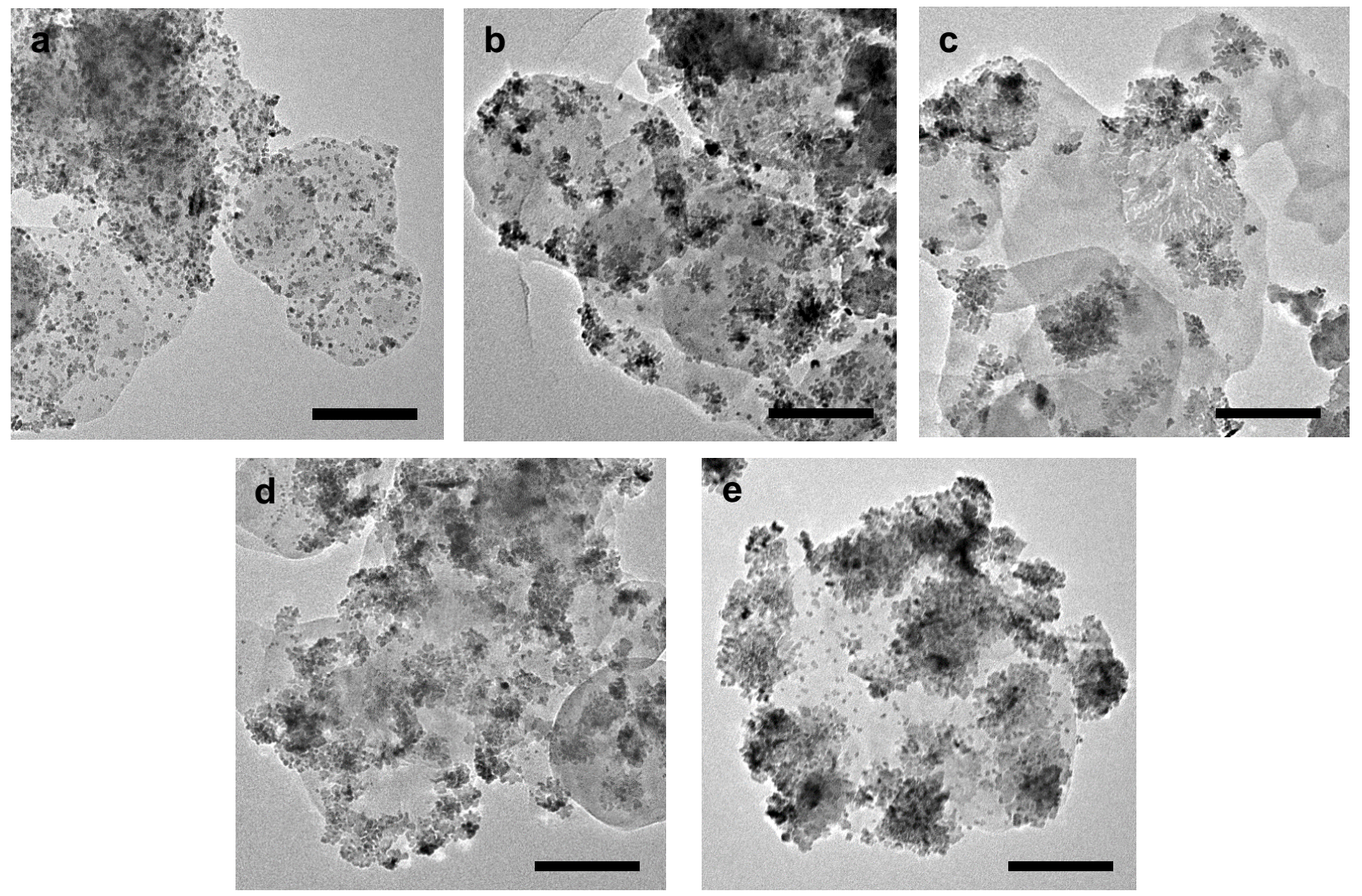

Figure S8. 2D-Pt growth using varied Pt-precursor amount. TEM image of Pt growth on

NiFe-LDH according to Pt precursor concentration of (a) 65.0, (b) 80.0, (c) 100.0, (d) 125.0 and (e) $150.0 \mathrm{mM}$ (scale bar: $100 \mathrm{~nm}$ ). In all the cases, $0.5 \mathrm{~mL}$ of NiFe-LDH $\left(10 \mathrm{mg} \mathrm{mL}^{-1}\right)$, $0.5 \mathrm{~mL}$ of $\mathrm{Na}_{2} \mathrm{PtCl}_{4} \cdot \mathrm{xH}_{2} \mathrm{O}$ solution with varying concentration, and $1.5 \mathrm{~mL}$ ascorbic acid solution $(33.3 \mathrm{mM})$ were used for the reaction at $70{ }^{\circ} \mathrm{C}$ for 10 min under stirring condition.

At lower $\mathrm{Pt}^{2+}$ precursor, multiple small sized Pt particles were formed on LDH surface (Figure $8 \mathrm{a}, \mathrm{b}$ ). With increasing the $\mathrm{Pt}^{2+}$ content, formation of small sized 2D-Pt were observed on the surface of LDH (Figure 8c), but to get full covering of LDH surface we further increase the $\mathrm{Pt}$ content in the growth solution, which causes the overgrowth of $\mathrm{Pt}$ in $z$-direction on LDH surface (Figure 8e). From this study, we fixed the amount of Pt-precursor $(0.5 \mathrm{~mL} ; 100.0 \mathrm{mM})$, and then moved to optimize the ratio of Pt precursor and AA to obtain perfectly shaped 2D-Pt covered on LDH template. 

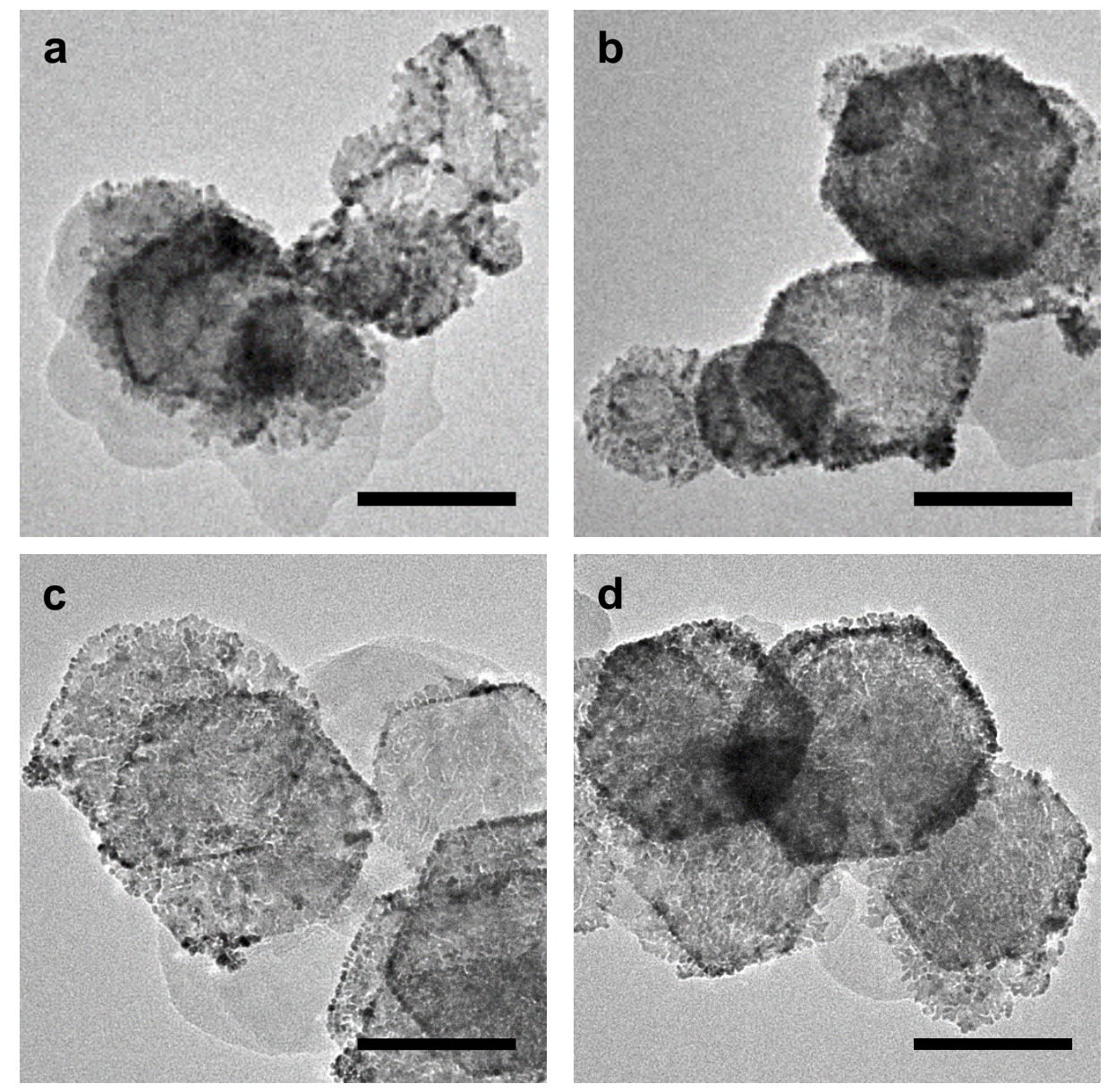

Figure S9. 2D-Pt growth using varied ascorbic acid amount. TEM images of 2D-Pt growth on NiFe-LDH according to ascorbic acid concentration of (a) 11.2, (b) 22.3, (c) 33.3 and (d) $44.5 \mathrm{mM}$ (scale bar: $100 \mathrm{~nm}$ ). In all the cases, $0.5 \mathrm{~mL}$ of NiFe-LDH $\left(10 \mathrm{mg} \mathrm{mL}^{-1}\right), 0.5 \mathrm{~mL}$ of $\mathrm{Na}_{2} \mathrm{PtCl}_{4} \cdot \mathrm{xH}_{2} \mathrm{O}(100 \mathrm{mM})$, and $1.5 \mathrm{~mL}$ ascorbic acid solution with varying concentration were used for the reaction at $70{ }^{\circ} \mathrm{C}$ for 10 min under stirring condition.

Although in all the cases 2D-Pt was observed on LDH surface, lesser amount of AA results in non-uniform 2D-Pt product. 

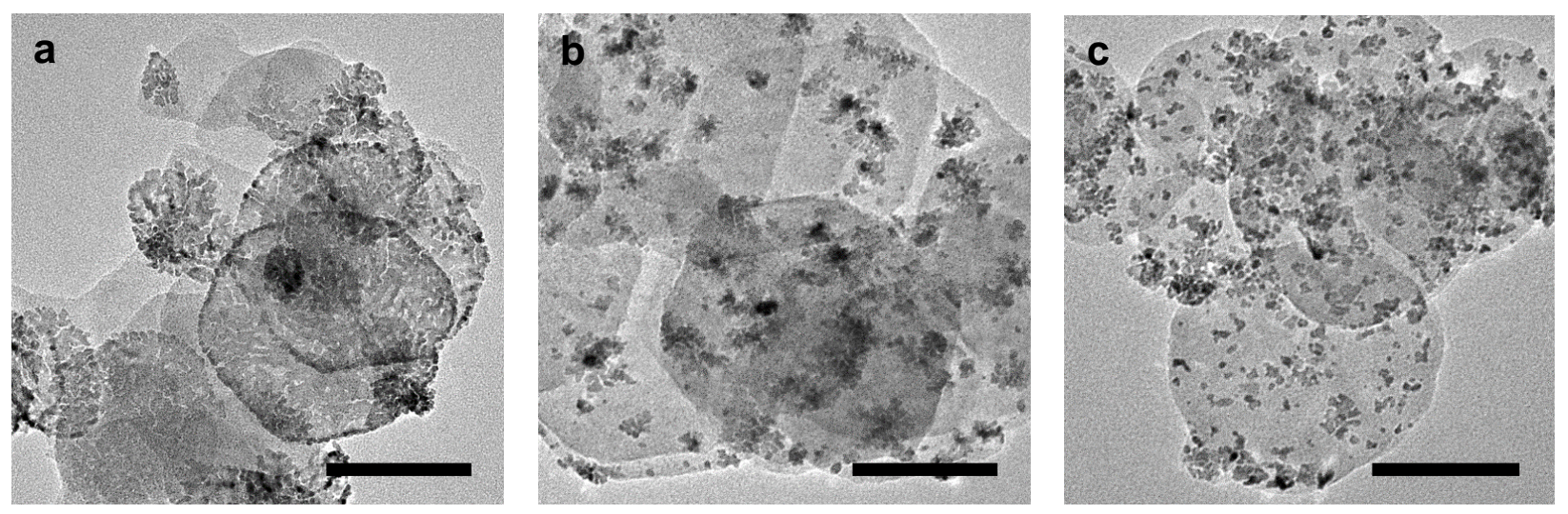

Figure S10. 2D-Pt growth under varied reaction temperatures. TEM images of 2D-Pt growth on NiFe-LDH according to temperature variation at (a) 70, (b) 75 and (c) $80{ }^{\circ} \mathrm{C}$ (scale bar: $100 \mathrm{~nm})$. In all the cases, $0.5 \mathrm{~mL}$ of NiFe-LDH $\left(10 \mathrm{mg} \mathrm{mL}^{-1}\right), 0.5 \mathrm{~mL}$ of $\mathrm{Na}_{2} \mathrm{PtCl}_{4} \cdot \mathrm{xH}_{2} \mathrm{O}$ $(100 \mathrm{mM})$, and $1.5 \mathrm{~mL}$ ascorbic acid solution $(33.3 \mathrm{mM})$ were used for the reaction at $70{ }^{\circ} \mathrm{C}$ for 10 min under stirring condition.

At high reaction temperature (like at $80{ }^{\circ} \mathrm{C}$ ), numerous Pt particles are found to form on LDH surface possibly due to relatively faster reduction of $\mathrm{Pt}^{2+}$ to form fast nucleation of $\mathrm{Pt}$ rather than their controlled growth as observed at $70{ }^{\circ} \mathrm{C}$. 

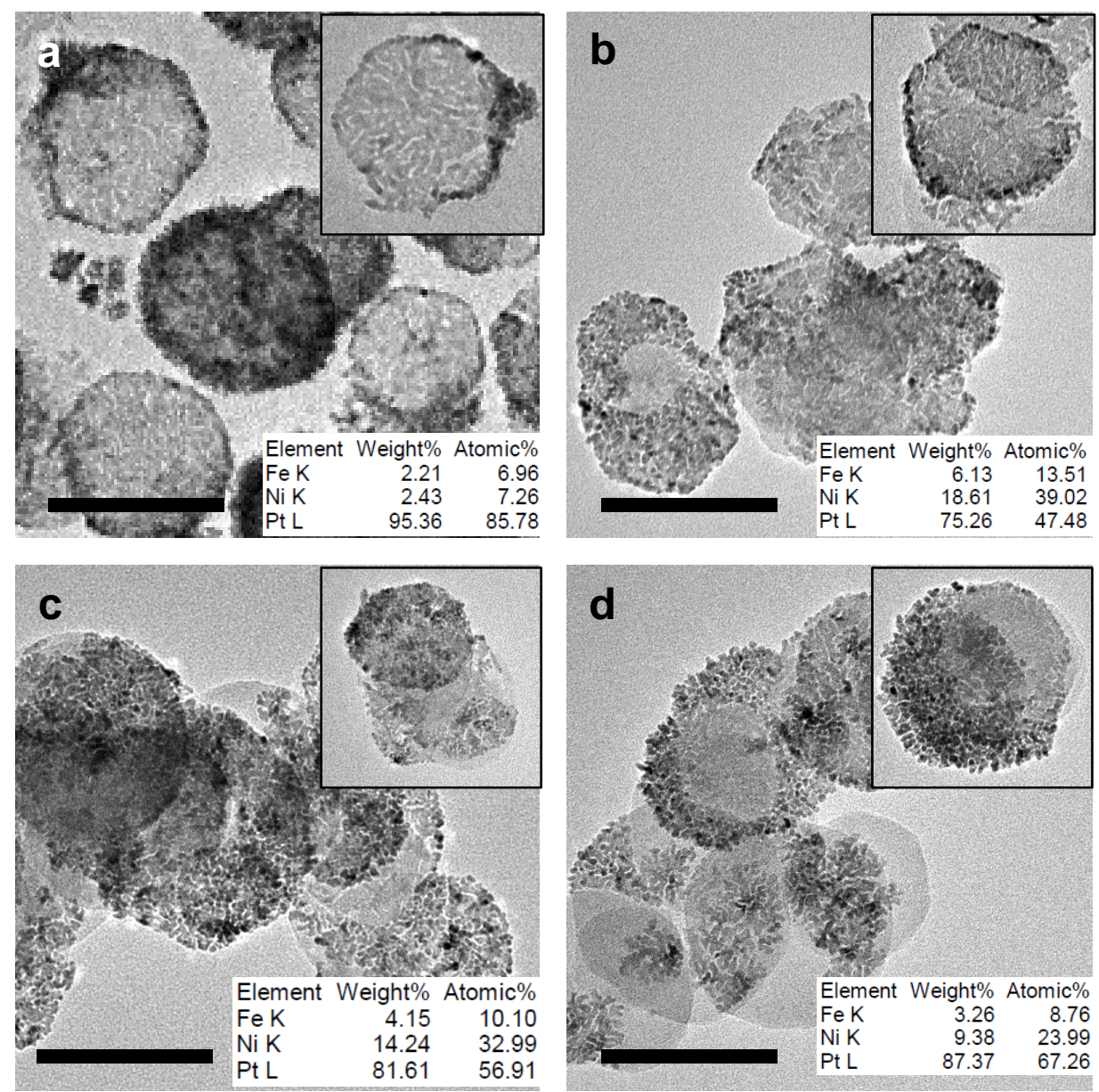

Figure S11. 2D-Pt growth under varied $\mathbf{p H}$ conditions. TEM images of LDH/2D-Pt at $\mathrm{pH}$ (a) 3.5, (b) 7.0, (c) 9.0 and (d) 11.0 (Scale bar : $100 \mathrm{~nm}$ ). Inset: EDS- elemental analysis. In all the cases, $0.5 \mathrm{~mL}$ of NiFe-LDH $\left(10 \mathrm{mg} \mathrm{mL}^{-1}\right), 0.5 \mathrm{~mL}$ of $\mathrm{Na}_{2} \mathrm{PtCl}_{4} \cdot \mathrm{xH}_{2} \mathrm{O}(100 \mathrm{mM})$, and 1.5 $\mathrm{mL}$ ascorbic acid solution $(33.3 \mathrm{mM})$ were used for the reaction at $70{ }^{\circ} \mathrm{C}$ for $10 \mathrm{~min}$ under stirring condition, but $\mathrm{pH}$ of the reaction mixture were first adjusted by dropwise addition of $0.1 \mathrm{M} \mathrm{NaOH}$ before heat treatment.

From the above TEM images of LDH/2D-Pt, the evolved Pt synthesized under acidic $(\mathrm{pH}=3.5)$ and neutral medium $(\mathrm{pH}=7.0)$ are found to be two-dimensional. In contrast, the reaction under alkaline reaction condition $(\mathrm{pH}=9.0$ and 11.0) form three-dimensional structures of Pt and aggregation of Pt NPs. Due to the leaching of Ni and Fe ions from LDH layer under acidic medium, the 2D-Pt under neutral medium becomes important. It is clear from the EDS-elemental analyses; Ni and Fe content in LDH/2D-Pt synthesized under neutral medium are identical with the material formed under alkaline $\mathrm{pH}$. Thus, the $\mathrm{pH}$ of the solution was critically optimized to maintain the 2D-Pt growth with preserving the LDH content in the synthesized hybrid. 

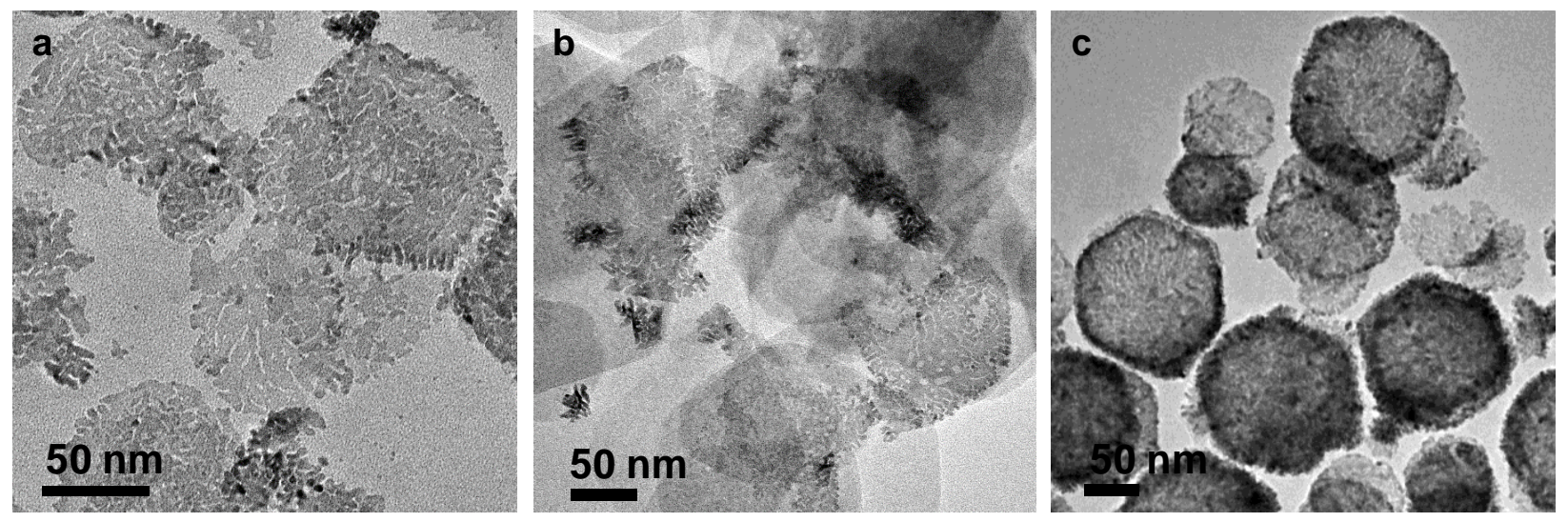

Figure S12. Effect of LDH for 2D-Pt growth. TEM images of 2D-Pt on (a) MgAl-LDH, (b) NiAl-LDH and (c) NiFe-LDH. In all the cases, $5.0 \mathrm{mg}$ of different LDHs (dispersed in $0.5 \mathrm{~mL}$ DI water), $0.5 \mathrm{~mL}$ of $\mathrm{Na}_{2} \mathrm{PtCl}_{4} \cdot \mathrm{xH}_{2} \mathrm{O}(100 \mathrm{mM})$, and $1.5 \mathrm{~mL}$ ascorbic acid solution (33.3 $\mathrm{mM}$ ) were used for the reaction at $70{ }^{\circ} \mathrm{C}$ for 10 min under stirring condition.

The synthetic process of these products using MgAl-LDH and NiAl-LDH templates was followed as same as the case for NiFe-LDH with only difference is the use of different LDHs. Regardless of the type of metal, 2D-Pt can grow in all LDHs. This is probably due to the interaction between the $\mathrm{LDH}$ functionalities and $\mathrm{Pt}^{2+}$ being crucial for $2 \mathrm{D}-\mathrm{Pt}$ growth. 

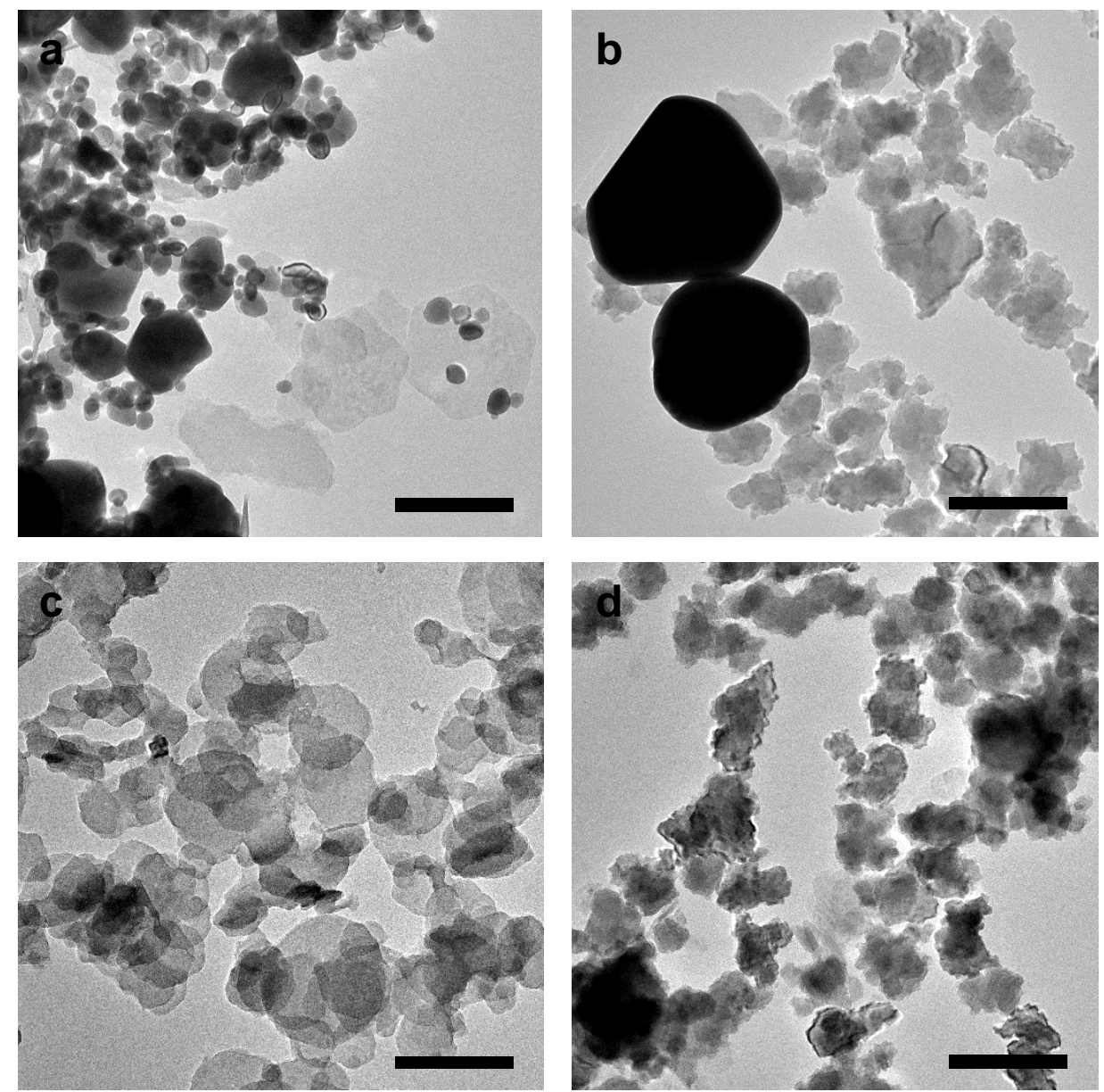

Figure S13. Synthetic process of A-LDH/2D-Pt for other metals. TEM images of 2D-metal growth study on NiFe-LDH using other metal such as (a) palladium, (b) gold, (c) iridium and (d) ruthenium (Scale bar : $100 \mathrm{~nm}$ ). In all the cases, $5.0 \mathrm{mg}$ of NiFe-LDH (dispersed in $0.5 \mathrm{~mL}$ DI water), $0.5 \mathrm{~mL}$ of metal-precursor $(100 \mathrm{mM})$, and $1.5 \mathrm{~mL}$ ascorbic acid solution $(33.3 \mathrm{mM})$ were used for the reaction at $70{ }^{\circ} \mathrm{C}$ for 10 min under stirring condition.

For other metals, the same precursor amount $(0.5 \mathrm{~mL} ; 100 \mathrm{mM})$ of the respective metals was used as for 2D-Pt case with keeping all other conditions unaltered. As per TEM images, they fail to attain two-dimensional growth pattern as observed for 2D-Pt. 

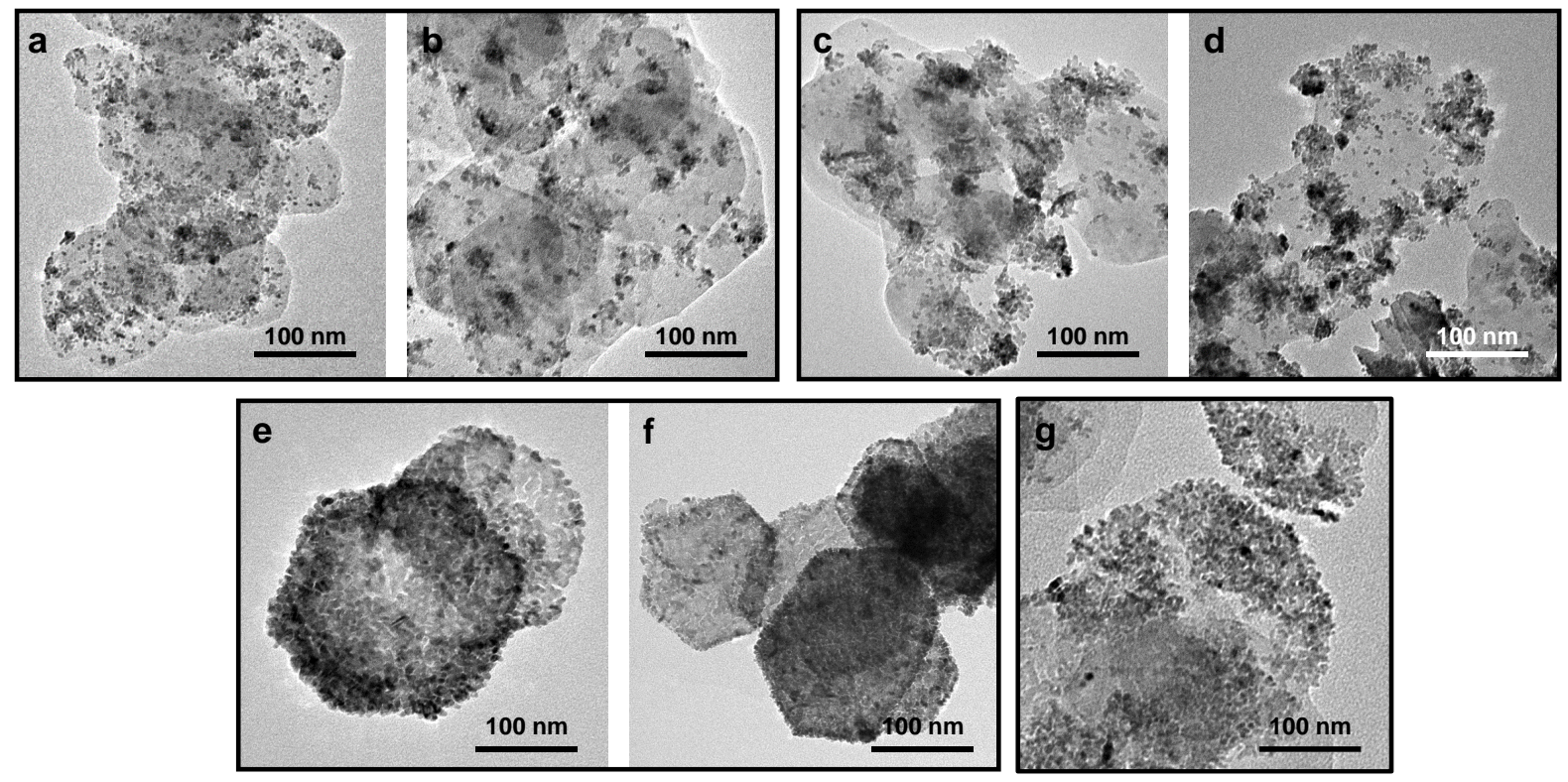

Figure S14. Attempt to control the pore size of 2D-Pt.

(a, b) TEM images of Pt grown under varying temperature at $80{ }^{\circ} \mathrm{C}$ (a) and $75{ }^{\circ} \mathrm{C} \mathrm{(b)}$; in all the cases, $0.5 \mathrm{~mL}$ of NiFe-LDH $\left(10 \mathrm{mg} \mathrm{mL}^{-1}\right), 0.5 \mathrm{~mL}$ of $\mathrm{Na}_{2} \mathrm{PtCl}_{4} \cdot \mathrm{xH}_{2} \mathrm{O}(100 \mathrm{mM})$, and $1.5 \mathrm{~mL}$ ascorbic acid solution $(33.3 \mathrm{mM})$ were used for $10 \mathrm{~min}$ of reaction under stirring condition.

(c, d) TEM images of Pt grown under varying Pt-precursor concentration of $125 \mathrm{mM}$ (c) and 150 (d) $\mathrm{mM}$; in all the cases, $0.5 \mathrm{~mL}$ of $\mathrm{NiFe}-\mathrm{LDH}\left(10 \mathrm{mg} \mathrm{mL}^{-1}\right), 0.5 \mathrm{~mL}$ of $\mathrm{Na}_{2} \mathrm{PtCl}_{4} \cdot \mathrm{xH}_{2} \mathrm{O}$, and $1.5 \mathrm{~mL}$ ascorbic acid solution $(33.3 \mathrm{mM})$ were used for $10 \mathrm{~min}$ of reaction $\left(70{ }^{\circ} \mathrm{C}\right)$ under stirring condition.

$(e, f)$ TEM images of Pt grown under varying ascorbic acid concentration of $44.5 \mathrm{mM}(\mathrm{e})$ and $89.9 \mathrm{mM}(\mathrm{f})$; in all the cases, $0.5 \mathrm{~mL}$ of NiFe-LDH $\left(10 \mathrm{mg} \mathrm{mL}^{-1}\right), 0.5 \mathrm{~mL}$ of $\mathrm{Na}_{2} \mathrm{PtCl}_{4} \cdot \mathrm{xH}_{2} \mathrm{O}$ $(100 \mathrm{mM})$, and $1.5 \mathrm{~mL}$ ascorbic acid solution were used for $10 \mathrm{~min}$ of reaction $\left(70{ }^{\circ} \mathrm{C}\right)$ under stirring condition.

(g) TEM images of Pt grown using preformed $\mathrm{Pt}(0)$-seed on LDH layers for the growth of 2D$\mathrm{Pt}$; for that reaction, $0.5 \mathrm{~mL}$ of NiFe-LDH $\left(10 \mathrm{mg} \mathrm{mL}^{-1}\right), 0.5 \mathrm{~mL}$ of $\mathrm{Na}_{2} \mathrm{PtCl}_{4} \cdot \mathrm{xH}_{2} \mathrm{O}(100$ $\mathrm{mM})$, and $1.5 \mathrm{~mL}$ ascorbic acid solution $(33.3 \mathrm{mM})$ were used for $10 \mathrm{~min}$ of reaction $\left(70{ }^{\circ} \mathrm{C}\right)$ under stirring condition.

In order to control the pore size of the formed 2D-Pt, we have applied various reaction conditions such as temperature variation, change in Pt-processor and AA to tune the reaction kinetics. However, in all the reactions Pt growth is happens to be either mesoporous two dimensional or formation of aggregated particles, even non-porous Pt were not formed in any cases. Precisely, the pore size of thee developed 2D-Pt (Figure S14e, f) is found to be in the same size of 3-5 $\mathrm{nm}$ as we described before. 


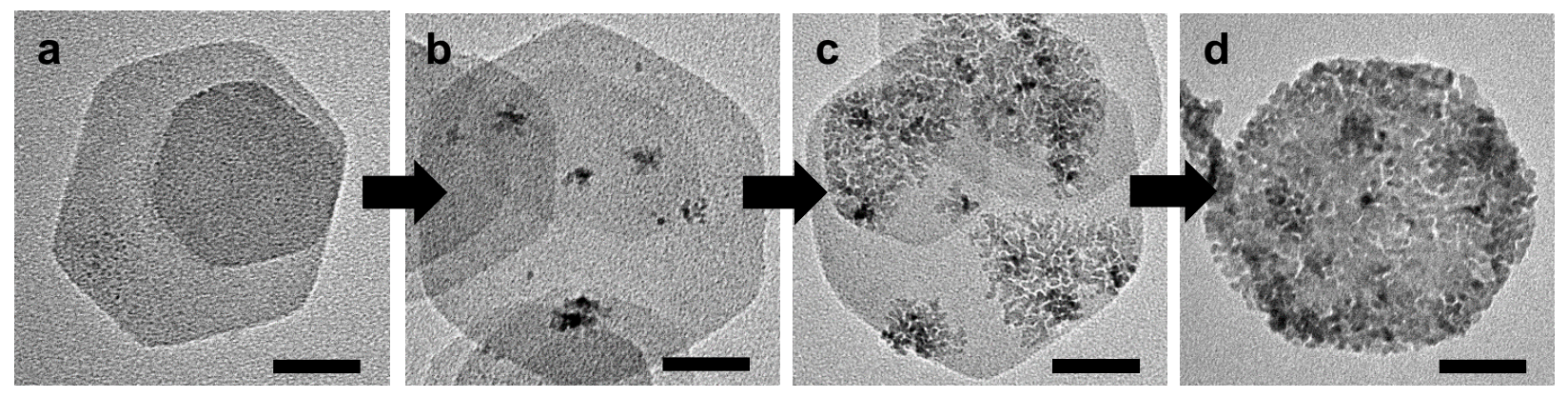

Figure S15. TEM analyses for various intermediates during N-LDH/2D-Pt formation.

TEM images for various intermediates, and the final product formed within 10 min of reaction for confirming growth mechanism of 2D-Pt in neutral media (N-LDH/2D-Pt). TEM images for (a) mixture of LDH and Pt precursors, and (b, c) various intermediates and (d) final product after $10 \mathrm{~min}$ of reaction (Scale bar $=30 \mathrm{~nm})$. In all the cases, $0.5 \mathrm{~mL}$ of NiFe-LDH $\left(10 \mathrm{mg} \mathrm{mL}^{-}\right.$ $\left.{ }^{1}\right), \quad 0.5 \mathrm{~mL}$ of $\mathrm{Na}_{2} \mathrm{PtCl}_{4} \cdot \mathrm{xH}_{2} \mathrm{O}(100 \mathrm{mM})$, and $1.5 \mathrm{~mL}$ ascorbic acid solution (33.3 mM) were used for the reaction at $70{ }^{\circ} \mathrm{C}$ for 10 min under stirring condition $(\mathrm{pH}=7.0)$.

\section{Ascorbic acid (AA)-induced reduction of $\mathrm{PtCl}_{4}{ }^{2-}$ under various $\mathrm{pH}$ medium:}

As shown in the following two half-cell reactions, the formal reduction potential value $(E)$ for ascorbic acid (AA) is highly dependent on solution $\mathrm{pH}$. According to Nernst equation, the reduction power of AA can be improved with increasing the solution $\mathrm{pH}$. Thus multiple seeding points have been originated due to faster nucleation of $\mathrm{Pt}$ under neutral condition in compassion to relatively weaker reduction capability of AA at low $\mathrm{pH}$. Previously, number of the nucleus and thus the size of the silver or gold nanoparticles were easily shown to be tunable by simply changing $\mathrm{pH}$ of the reaction systems. ${ }^{7,8}$

Half-cell reactions:

Standard Redox potential $\left(E^{0}\right)$ at $298 \mathrm{~K}$ and $1 \mathrm{~atm}$

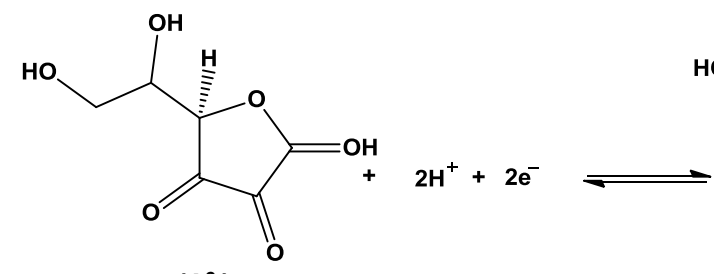

$\left(A^{2-}\right)$

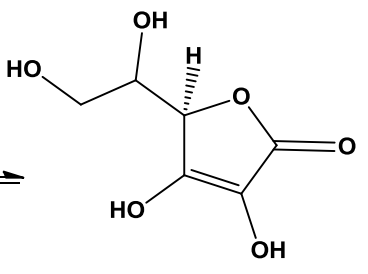

(AA)

$$
\left[\mathrm{PtCl}_{4}\right]^{2^{-}}+2 \mathrm{e}^{-} \rightleftharpoons \mathrm{Pt}+4 \mathrm{Cr}
$$

$0.41 \mathrm{~V}$

$0.75 \mathrm{~V}$

Nernst Equation:

$$
E=E^{0}-\frac{0.059}{2} \ln \frac{[A A]}{\left[A^{2^{-}}\right]\left[H^{+}\right]^{2}} \quad=E^{0}-\frac{0.059}{2} \ln \frac{[A A]}{\left[A^{2^{-}}\right]}-\frac{0.059}{2}(2) \mathrm{pH}
$$



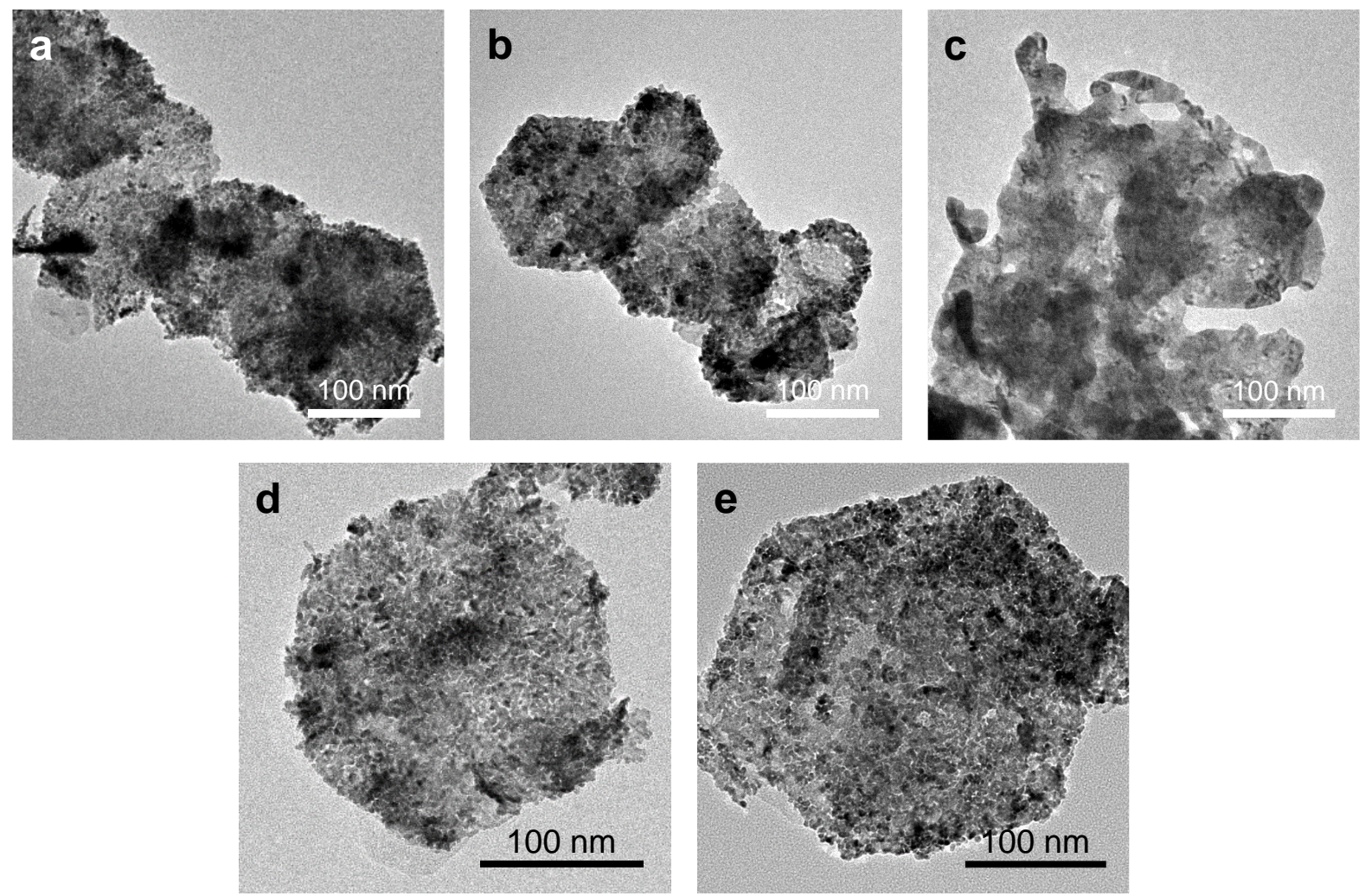

Figure S16. Stability of N-LDH/2D-Pt under varied conditions. TEM images of NLDH/2D-Pt after heat treatment at (a) $100{ }^{\circ} \mathrm{C}$ (Ar/1 h), (b) $100{ }^{\circ} \mathrm{C}\left(4 \% \mathrm{H}_{2}\right.$ in $\left.\mathrm{Ar} / 1 \mathrm{~h}\right)$ and (c) $300{ }^{\circ} \mathrm{C}\left(4 \% \mathrm{H}_{2}\right.$ in $\left.\mathrm{Ar} / 5 \mathrm{~h}\right)$. TEM images of N-LDH/2D-Pt stored as (d) powdered form and (e) suspension in ethanol for 6 months under ambient condition.

To check the stability of N-LDH/2D-Pt, the hybrid material was subjected to various thermal treatment like heating at $100{ }^{\circ} \mathrm{C}$ (under $\mathrm{Ar}$ and $4 \% \mathrm{H}_{2}$ in $\mathrm{Ar}$ ) and $300{ }^{\circ} \mathrm{C}$ (under $4 \% \mathrm{H}_{2}$ in Ar). As shown in Figure S16a-b, two dimensional morphology of the material is stable even after heating at $100{ }^{\circ} \mathrm{C}$ irrespective of gas environment, while under heating at higher temperature like $300{ }^{\circ} \mathrm{C}(5 \mathrm{~h})$, the nanostructures get damaged (Figure S16c). In addition, the thin 2D-Pt grown on LDH layers remains stable without any discernable change for more than 6 months both in powder form and in ethanol suspension (Figure S16d-e), thus suggesting its sufficient stability for practical use. 
a

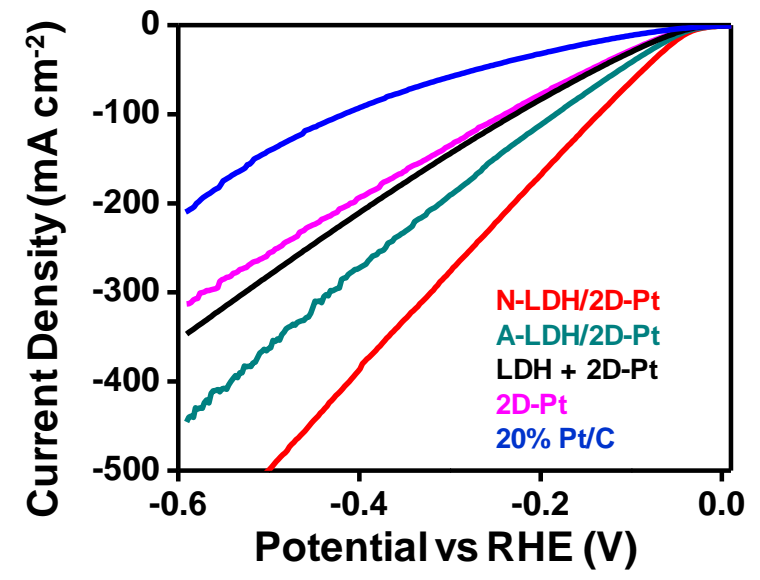

b

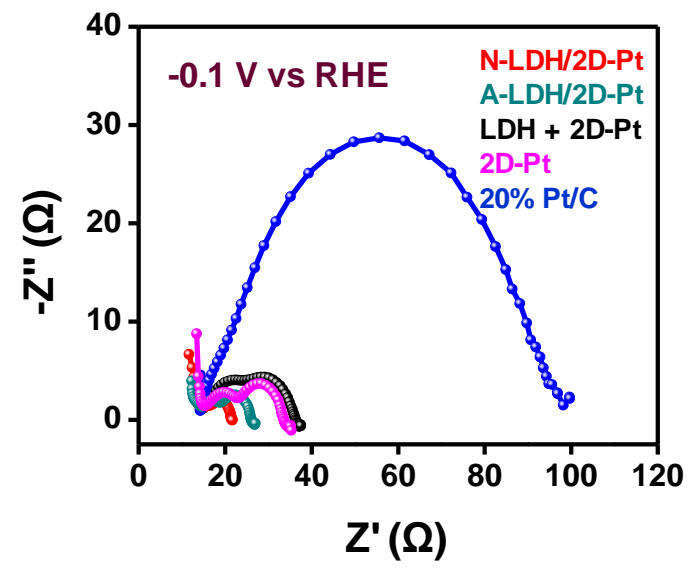

Figure S17. HER electrocatalysis using various catalysts. (a) LSV profiles without any $i R$ correction for all the tested catalysts and (b) their corresponding EIS graph. 

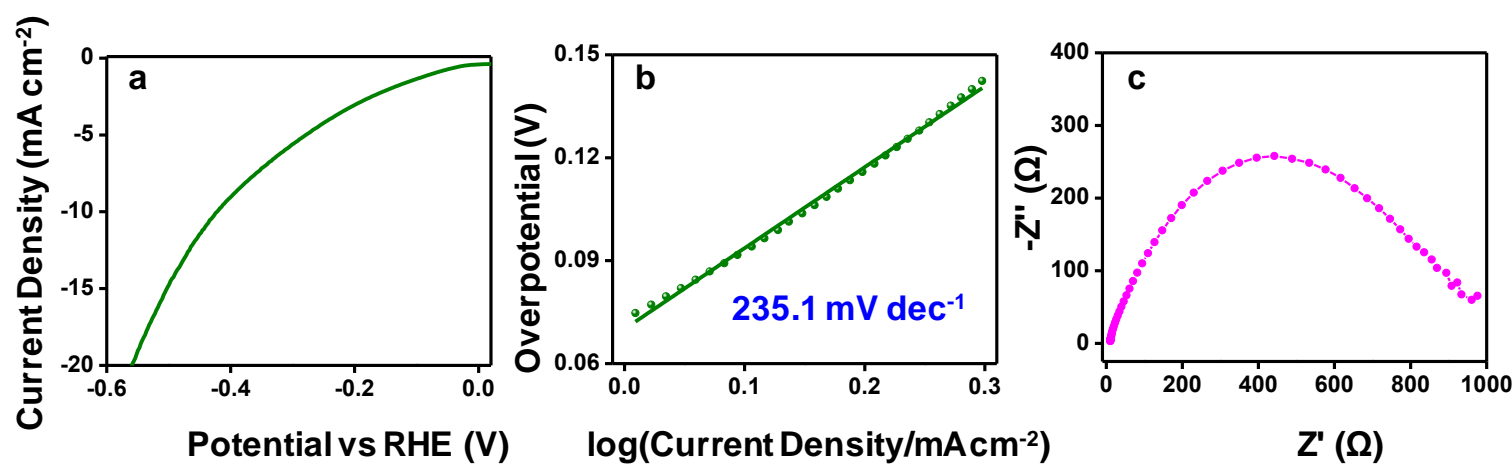

Figure S18. NiFe-LDH as HER electrocatalyst. Electrochemical HER for NiFe-LDH material: (a) 70\% iR-corrected LSV profile, (b) corresponding Tafel plot, and (c) EIS plot at $0.1 \mathrm{~V} v s$ RHE. All the studies were carried out in $1.0 \mathrm{M} \mathrm{KOH}$ electrolyte (catalyst mass loading at electrode $=0.214 \mathrm{mg} \mathrm{cm}^{-2}$ ).

It is worth noting that NiFe-LDH has very poor HER activity as described from the above results. 

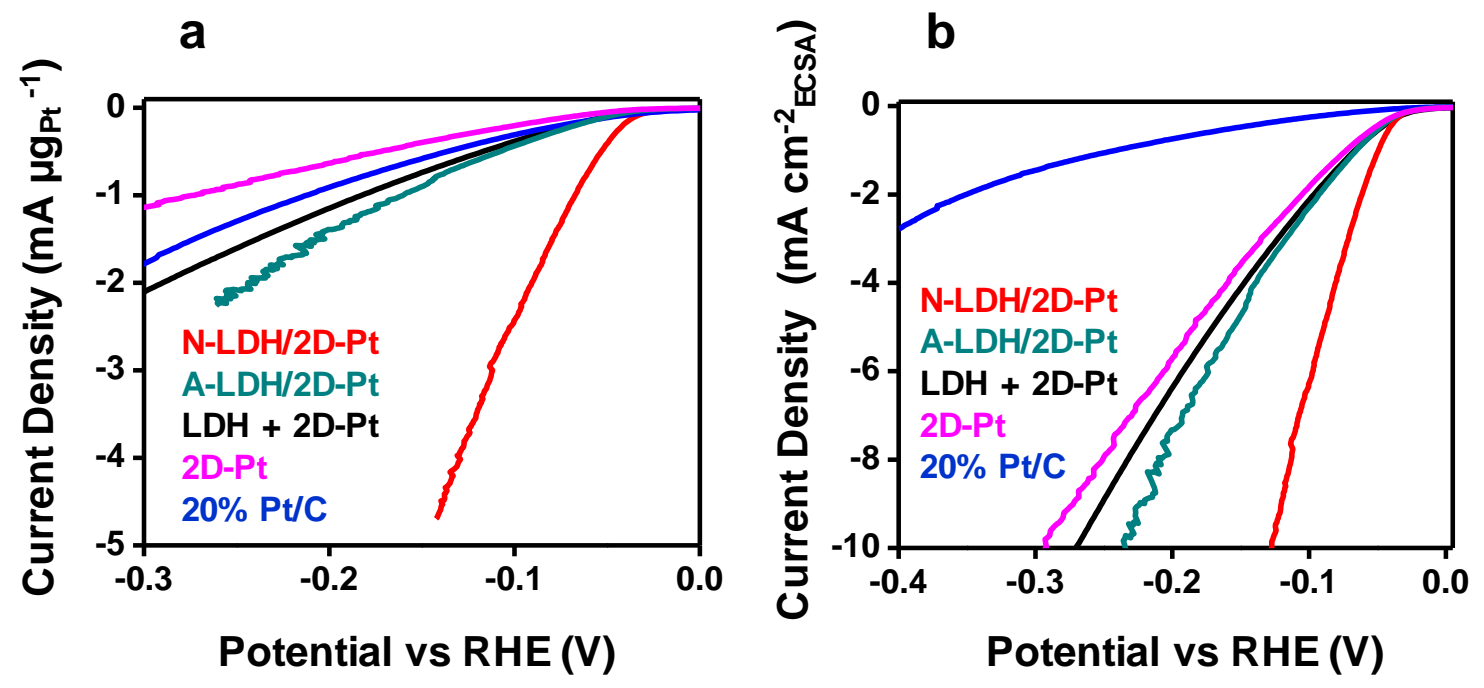

Figure S19. Importance of N-LDH/2D-Pt compared to other tested catalysts. (a) Pt mass normalized and (b) ECSA-normalized LSV plots for all the tested electrocatalysts. 

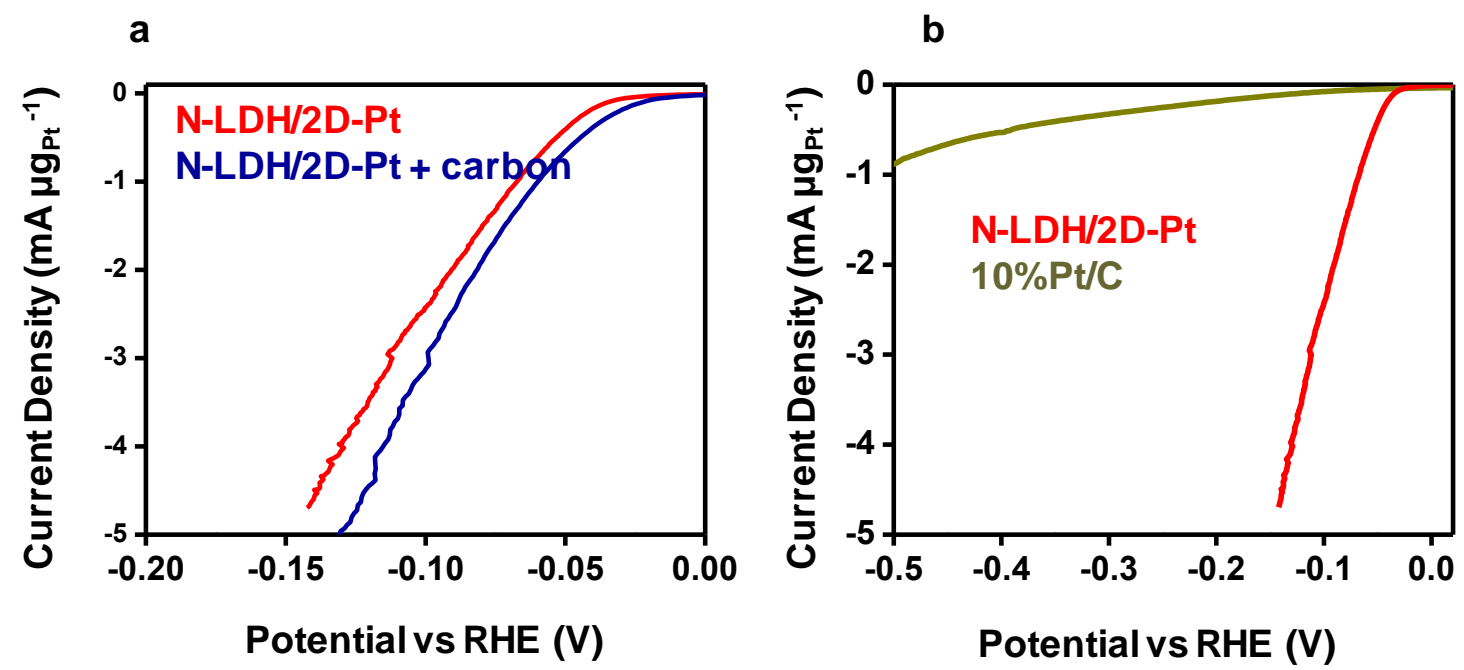

Figure S20. Superior performance of N-LDH/2D-Pt than commercial catalyst $10 \% \mathrm{Pt} / \mathrm{C}$. Comparative Pt mass normalized LSV profiles for N-LDH/2D-Pt with (a) N-LDH/2D-Pt + carbon and (b) commercial 10\% Pt/C.

Here to prepare the carbon-incorporated electrode, the electrocatalyst (N-LDH/2D-Pt) and carbon black were mixed in 2:3 weight ratio before preparing a $3 \mathrm{mg} \mathrm{mL}^{-1}$ catalyst dispersion for drop casting in RDE-GC electrode. 
a

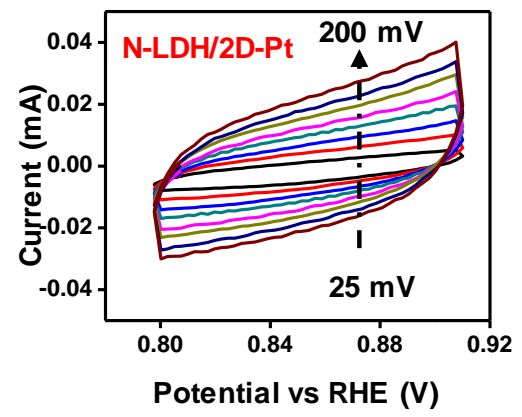

d

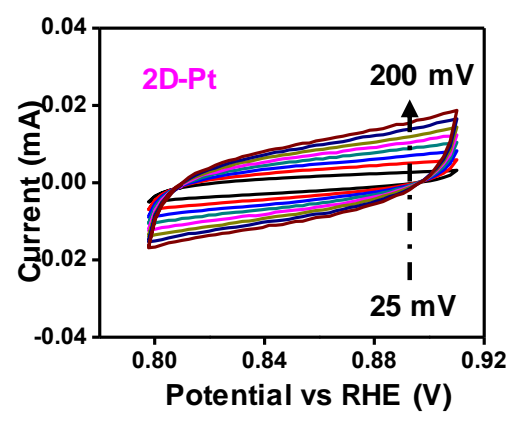

b

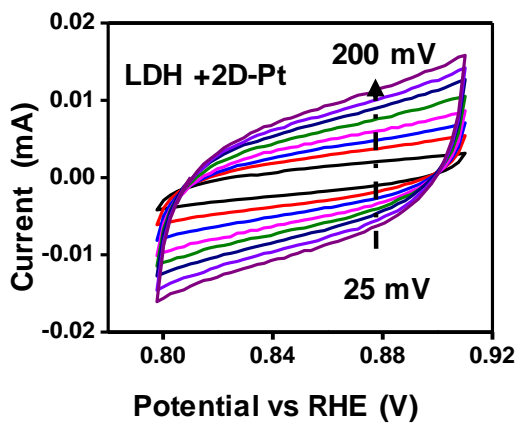

e

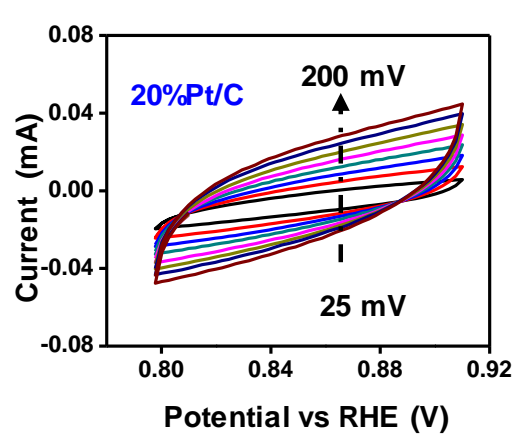

C
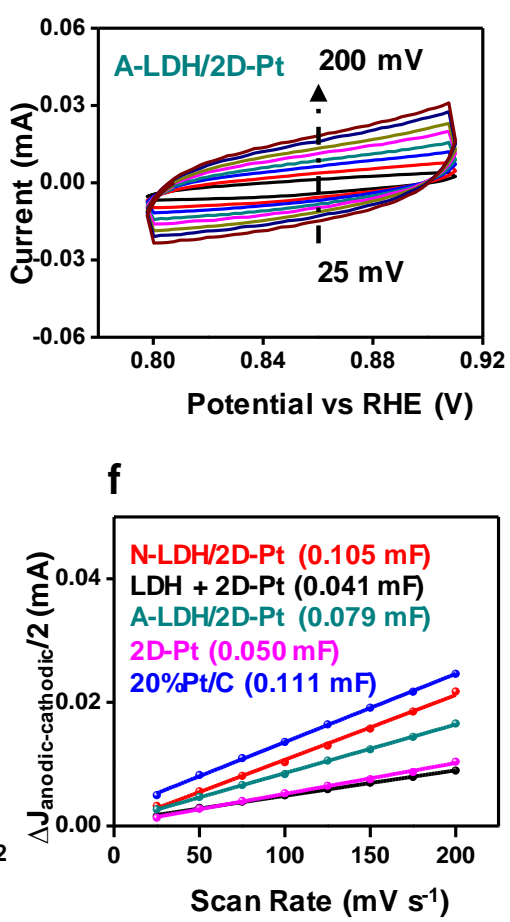

Figure S21. Electrochemical surface area (ECSA) calculation for various catalysts. CV curves of (a) N-LDH/2D-Pt, (b) LDH + 2D-Pt, (c) A-LDH/2D-Pt, (d) 2D-Pt, (e) 20\% Pt/C. All the samples were measured in a non-Faradaic region at the following scan rate: 25, 50, 75, $100,125,150,175$ and $200 \mathrm{mV} \mathrm{s}^{-1}$ (sequentially increase with the direction of arrow). (f) Linear fitting of the capacitive currents at $0.861 \mathrm{~V} v s$ RHE as a function of scan rate for all the samples (inset; $\mathrm{C}_{\mathrm{dl}}$ values of the catalysts).

Presence of LDH in the hybrid material is crucial to enable easy interactions with the $\mathrm{OH}^{-}$ions present in the electrolyte to achieve high double layer capacitance in N-LDH/2D-Pt. ${ }^{9}$ It is important to note that $\mathrm{LDH}$ content in various substrate varies from $\sim 36,7$ and $0 \%$ for $\mathbf{N}$ LDH/2D-Pt, A-LDH/2D-Pt and 2D-Pt, respectively. For N-LDH/2D-Pt, presence of high quantity of LDH and strong interface formation in LDH@2D-Pt in comparison to A-LDH/2DPt and 2D-Pt have resulted in such high ECSA value for N-LDH/2D-Pt. Much lower ECSA value for physical mixture $[\mathrm{LDH}+\mathbf{2 D}-\mathbf{P t}]$ can be explained from poor physical contact between the two components compared to in-situ generated hybrid materials. On the other hand, in commercial $\mathrm{Pt} / \mathrm{C}$ catalyst, carbon support with expected high surface area, allows easy $\mathrm{KOH}$ electrolyte absorption and also provide remarkable electrical conductivity to achieve high ECSA value for Pt/C close to N-LDH/2D-Pt. 
(a)

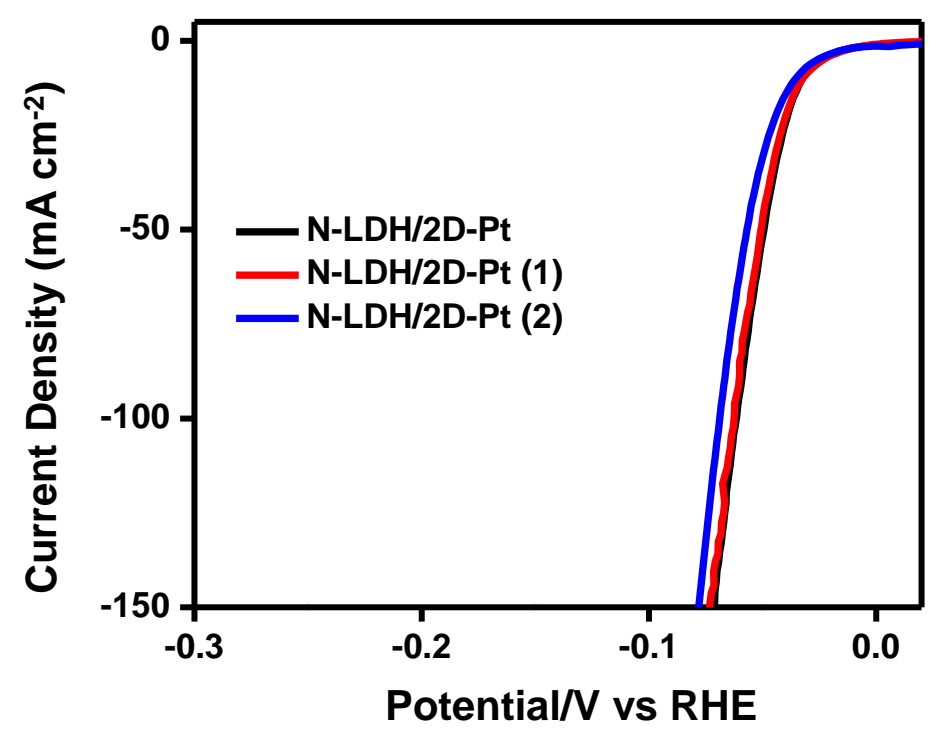

(b)

N-LDH/2D-Pt N-LDH/2D-Pt (1) N-LDH/2D-Pt (2)

\begin{tabular}{cccc}
\hline $\begin{array}{c}\text { Overpotential at } 10 \mathrm{~mA} \mathrm{~cm}^{-2} \\
\left(\eta_{10} / \mathrm{mV}\right)\end{array}$ & 31 & 32 & 34 \\
$\begin{array}{c}\text { Overpotential at } 100 \mathrm{~mA} \mathrm{~cm}^{-2} \\
\left(\eta_{100} / \mathrm{mV}\right)\end{array}$ & 61 & 61 & 68 \\
\hline
\end{tabular}

Figure S22. Reproducibility test for electrochemical HER by N-LDH/2D-Pt synthesized under different batches. (a) LSV profiles and (b) the obtained results in tabulated form by three different batches of N-LDH/2D-Pt.

Importantly, the HER results are highly reproducible with less than $10 \mathrm{mV}$ change in overpotential for $100 \mathrm{~mA} \mathrm{~cm}^{-2}$ current density. 


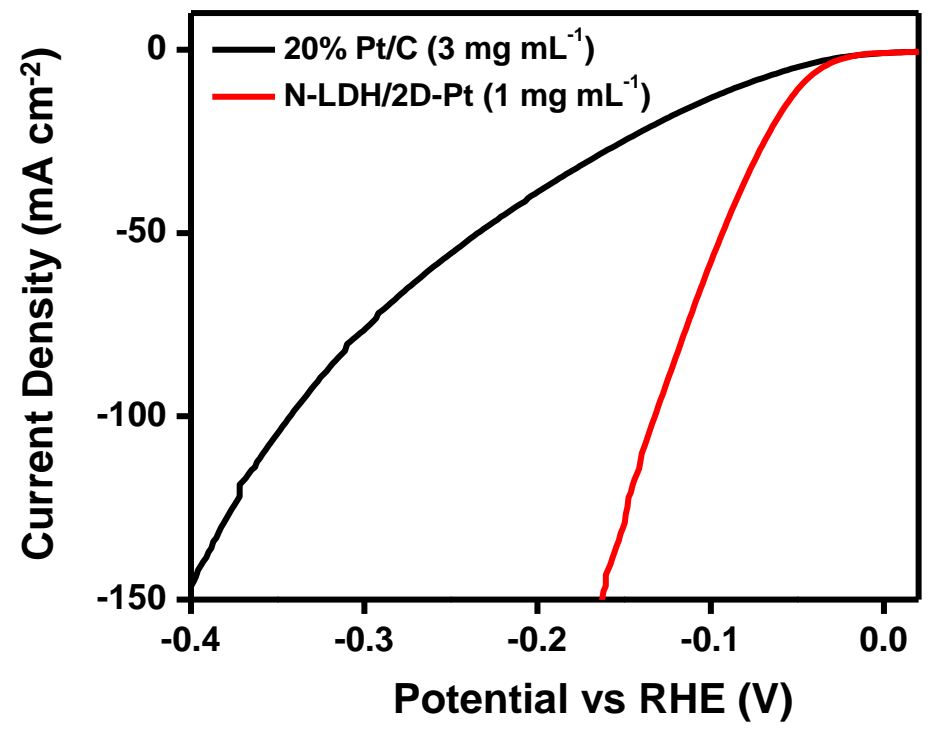

Figure S23. HER performance of N-LDH/2D-Pt with lower Pt loading on GCE.

With considering the Pt content in N-LDH/2D-Pt as $\sim 64.28 \%$, we have studied the HER activity with $1 \mathrm{mg} \mathrm{mL}^{-1}$ catalyst dispersion. Thus, we maintain the Pt loading on GCE same like commercial Pt/C. Precisely, the Pt loading in N-LDH/2D-Pt and 20\% Pt/C electrode become 0.045 and $0.043 \mathrm{mg} \mathrm{cm}^{-2}$, respectively.

From the $i$ R-corrected LSV profiles, superiority of our synthesized hybrid material over commercial catalyst is clear. 


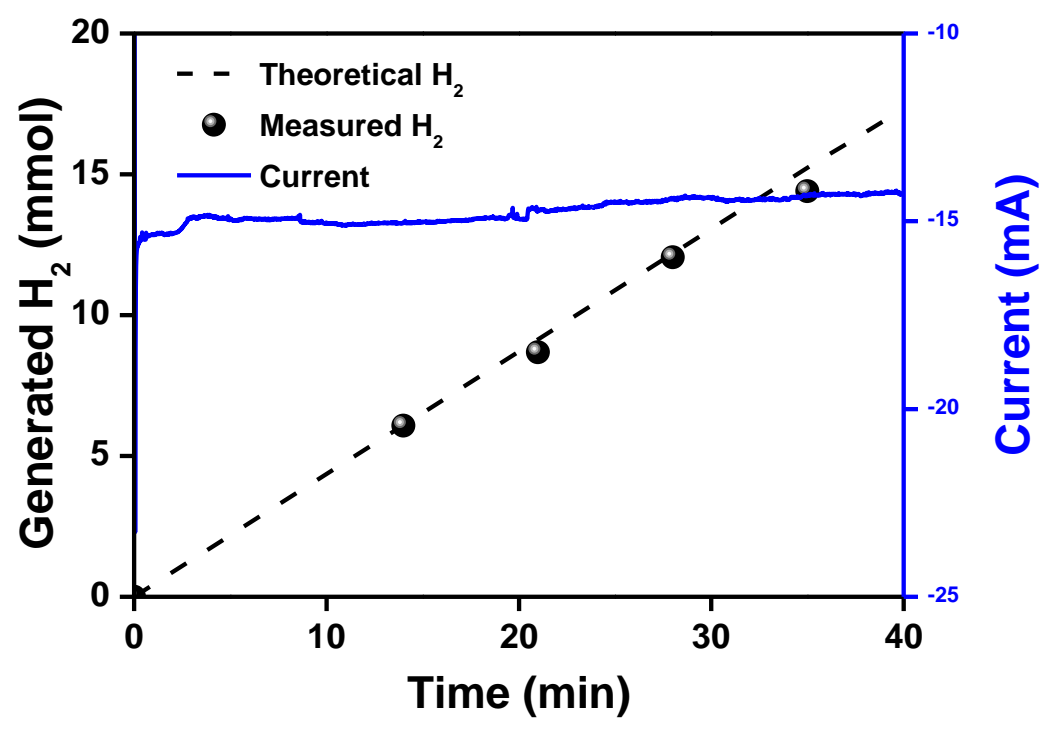

Figure S24. Measurement of hydrogen gas generated through HER. Plot of the amount of experimentally measured and theoretically calculated $\mathrm{H}_{2}$ versus time for N-LDH/2D-Pt at $0.06 \mathrm{~V} v s$ RHE. All the studies were carried out in $1.0 \mathrm{M} \mathrm{KOH}$ electrolyte. Here the theoretically calculated $\mathrm{H}_{2}$ is estimated from the obtained current during the gas measurement experiment, which is $\sim 14 \mathrm{~mA}$ in this case.

Here the calculated faradaic efficiency (FE) is $97.0 \pm 2.3 \%$. 

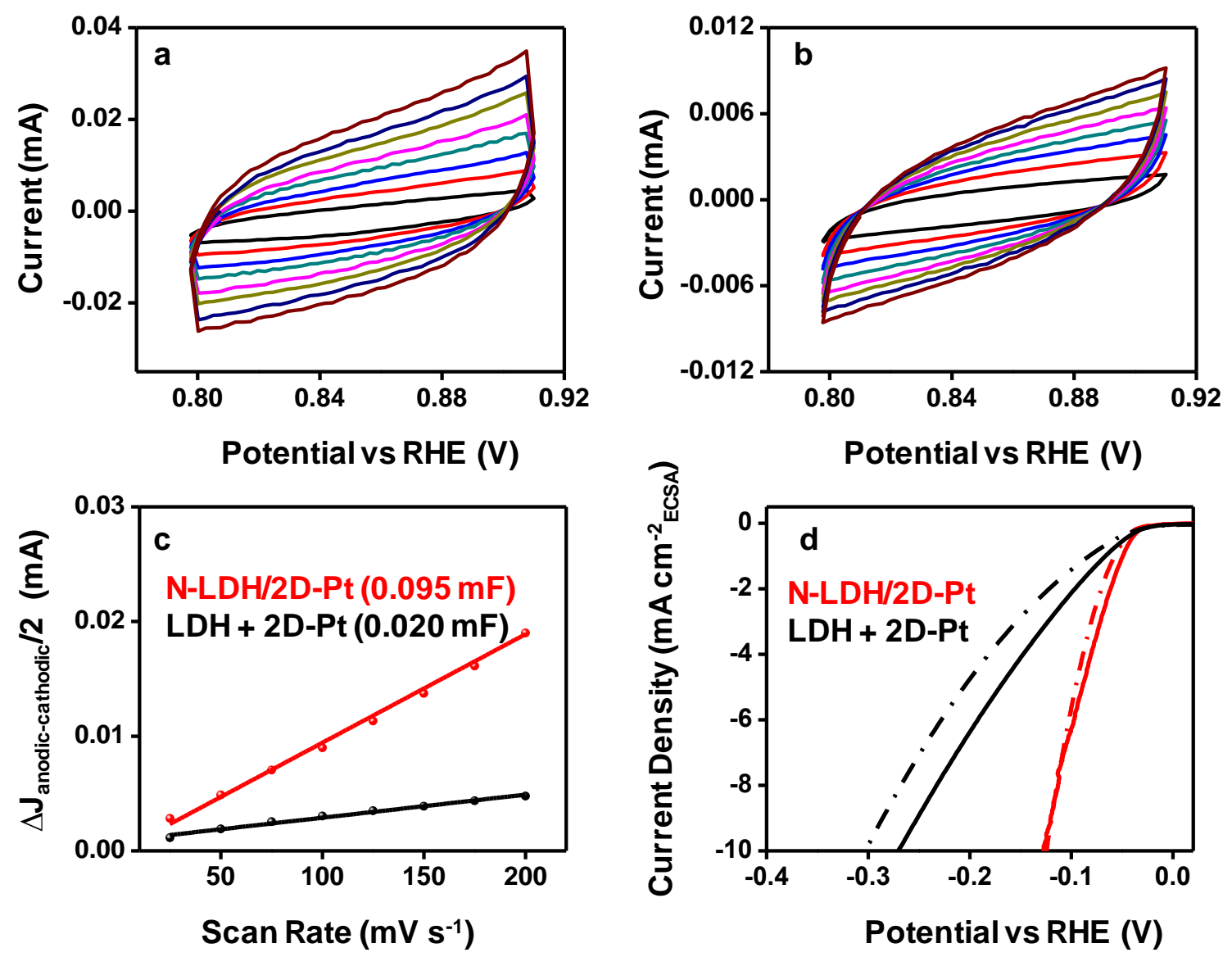

Figure S25. Importance of N-LDH/2D-Pt in stability test than physical mixture. CV curves of (a) N-LDH/2D-Pt, (b) [LDH + 2D-Pt] after $5000 \mathrm{CV}$ cycles for HER. (c) The corresponding linear fitting of the capacitive currents at $0.861 \mathrm{~V} v s$ RHE as a function of scan rate for the after catalysis samples (inset; $\mathrm{C}_{\mathrm{dl}}$ values of the catalysts). (d) ECSA-normalized LSV profiles for cyclic stability tests using N-LDH/2D-Pt (red) and physical mixture [LDH + 2D-Pt] (black) [fresh catalysts (solid line) and after CV cycles (dotted line)].

After CV cycles, ECSA value changes from 3.48 to $3.17 \mathrm{~cm}^{2}$ for N-LDH/2D-Pt, whereas for physical mixture the ECSA sharply reduced to 0.67 from $1.35 \mathrm{~cm}^{2}$. In the ECSA normalized polarization curves, N-LDH/2D-Pt is found to be unchanged after CV cycles suggesting the importance of its strong interface formation for performing highly stable HER performance, while physical mixture sample lacks such stability. 


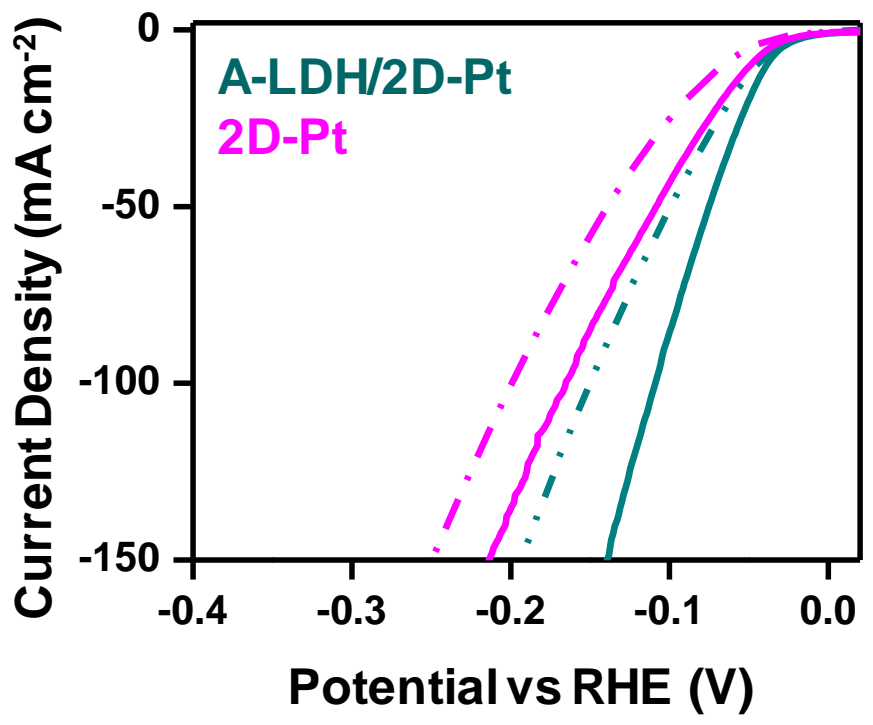

Figure S26. Stability test of other samples. HER cyclic stability test for various catalysts [solid line; fresh catalyst and dotted line; after $5000 \mathrm{CV}$ cycles]. Both the samples exhibit lowering of HER performance after CV cycles. 

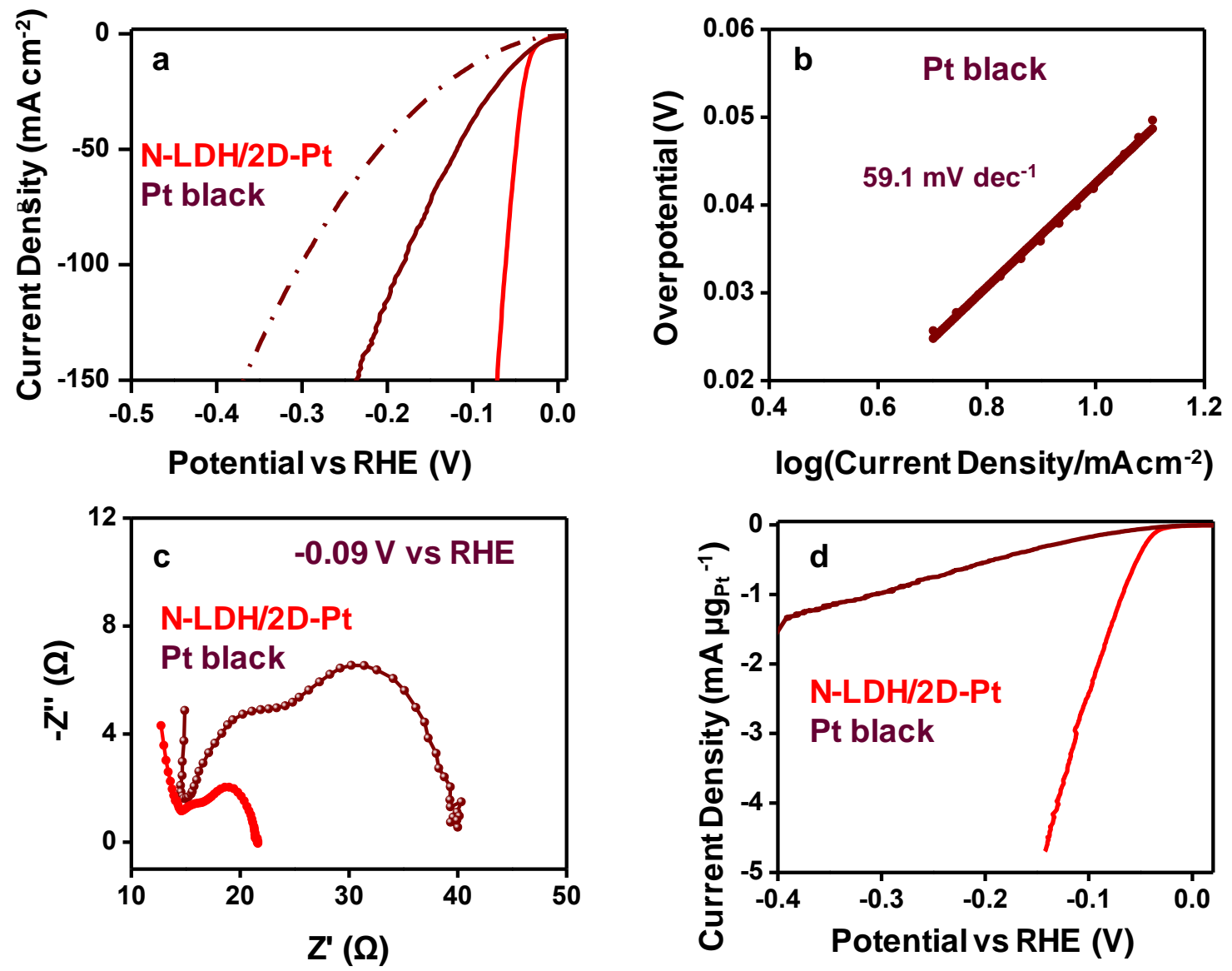

Figure S27. Superior performance from N-LDH/2D-Pt than Pt black. (a) Comparative HER performance for N-LDH/2D-Pt (fresh catalyst) and Pt black (solid line; fresh catalyst and dotted line; after $5000 \mathrm{CV}$ cycles), (b) Tafel plot for fresh Pt black sample. Comparative (c) EIS plot at -0.1 V vs RHE and (d) Pt mass normalized LSV profiles for fresh Pt black and NLDH/2D-Pt. 


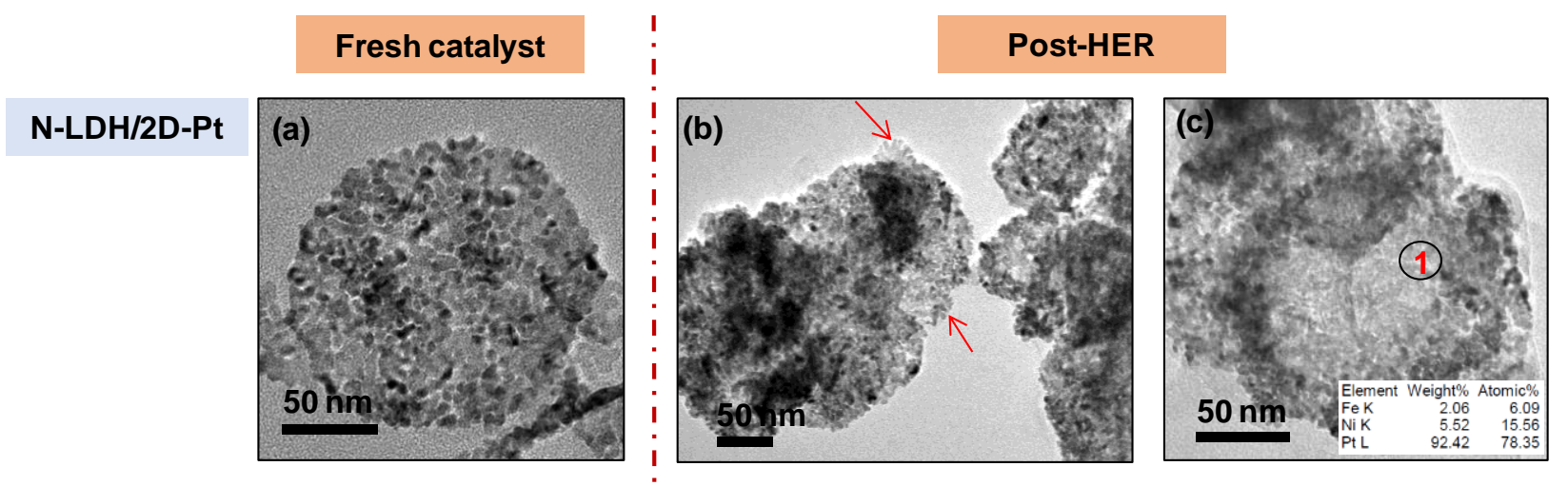

Figure S28. Post-HER analyses for N-LDH/2D-Pt. TEM images of (a) fresh and (b, c) postHER catalysts for N-LDH/2D-Pt.

TEM analyse of post-HER N-LDH/2D-Pt sample show presence of thin Pt sheets (indicated by red arrows in Figure S28b). The overall size and thickness of the Pt sheets on $\mathrm{LDH}$ remain unchanged and ratio of $\mathrm{Ni} / \mathrm{Fe}$ found to be unaltered as shown in EDS-result (inset; Figure S28c). 
Table S1.Tabulated form of HER performance of all the electrocatalysts tested in this study.

\begin{tabular}{|c|c|c|c|c|c|}
\hline Materials & $\begin{array}{l}\text { Pt loading } \\
\left(\mathrm{mg} \mathrm{cm}^{-2}\right)\end{array}$ & $\begin{array}{c}\text { Overpotential at } \\
10 \mathrm{~mA} \mathrm{~cm}^{-2} \\
\left(\eta_{10}\right) / \mathrm{mV}\end{array}$ & $\begin{array}{c}\text { Overpotential at } \\
100 \mathrm{~mA} \mathrm{~cm}^{-2} \\
\left(\eta_{100}\right) / \mathrm{mV}\end{array}$ & $\begin{array}{l}\text { Tafel slope } \\
\left(\mathrm{mV} \operatorname{dec}^{-1}\right)\end{array}$ & $\begin{array}{c}\text { Exchange } \\
\text { Current Density } \\
\left.\qquad(\mathbf{m A ~ c m})^{-2}\right)\end{array}$ \\
\hline N-LDH/2D-Pt & 0.132 & 31 & 61 & 32.3 & 1.12 \\
\hline $\mathrm{A}-\mathrm{LDH} / 2 \mathrm{D}-\mathrm{Pt}$ & 0.198 & 38 & 111 & 39.7 & 0.92 \\
\hline $2 \mathrm{D}-\mathrm{Pt}$ & 0.214 & 50 & 165 & 44.1 & 0.68 \\
\hline $20 \% \mathrm{Pt} / \mathrm{C}$ & 0.043 & 82 & 342 & $67.7^{10,11}$ & 0.90 \\
\hline $\begin{array}{c}{[\mathrm{LDH}+\mathbf{2 D - P t}]} \\
(1: 1)\end{array}$ & 0.107 & 51 & 173 & 40.3 & 0.63 \\
\hline
\end{tabular}


Table S2. Tabulated form for mass activity and specific activities of HER performance from all the electrocatalysts tested in this study.

\begin{tabular}{|c|c|c|c|c|}
\hline Materials & $\begin{array}{c}\text { Mass Activity } \\
\left(\mathrm{mA} \mu \mathrm{g}^{-1}\right) \text { at } \\
\mathbf{- 0 . 0 7} \mathrm{V} \text { vs RHE }\end{array}$ & $\begin{array}{l}\text { Mass Activity } \\
\left(\mathrm{mA} \mu \mathrm{g}^{-1}\right) \text { at } \\
-0.1 \mathrm{~V} \text { vs RHE }\end{array}$ & $\begin{array}{l}\text { ECSA } \\
\left(\mathrm{cm}^{2}\right)\end{array}$ & $\begin{array}{l}\text { Specific Activity } \\
\left(\mathrm{mA} \mathrm{cm}^{-2}\right) \text { at } \\
-0.07 \text { V vs RHE }\end{array}$ \\
\hline N-LDH/2D-Pt & 1.11 & 2.43 & 3.48 & 2.87 \\
\hline $\mathrm{A}-\mathrm{LDH} / 2 \mathrm{D}-\mathrm{Pt}$ & 0.22 & 0.44 & 2.62 & 1.16 \\
\hline 2D-Pt & 0.11 & 0.21 & 1.66 & 0.95 \\
\hline $20 \% \mathrm{Pt} / \mathrm{C}$ & 0.18 & 0.31 & 3.68 & 0.15 \\
\hline $\begin{array}{c}{[\mathrm{LDH}+2 \mathrm{D}-\mathrm{Pt}]} \\
(1: 1)\end{array}$ & 0.21 & 0.38 & 1.35 & 1.14 \\
\hline
\end{tabular}


Table S3.Mass activity for various tested catalysts at $-0.07 \mathrm{~V} v s$ RHE.

\begin{tabular}{cc} 
Materials & $\begin{array}{c}\text { Mass Activity }\left(\mathbf{m A ~} \mu \mathbf{g}^{-1}\right) \\
\text { at } \mathbf{- 0 . 0 7} \text { V vs } \mathbf{R H E}\end{array}$ \\
\hline N-LDH/2D-Pt & 1.11 \\
N-LDH/2D-Pt + carbon & 1.40 \\
$(2: 3)$ & \\
Pt black & 0.10 \\
$10 \%$ Pt/C & 0.058
\end{tabular}

It is clear for the above table that N-LDH/2D-Pt has $\sim 11.0$ and 19.1 times higher activity than commercial Pt black and 10\% Pt on graphitized carbon, respectively. In addition, mixing carbon black (Vulcan XC 72R) leads 1.26 times higher activity improvement for N-LDH/2DPt. 
Table S4. $\mathrm{R}_{\mathrm{ct}}$ and $\mathrm{R}_{\mathrm{p}}$ values for various catalysts determined from EIS at $-0.1 \mathrm{~V}$ vs RHE as shown in Figure 14b.

\begin{tabular}{ccc} 
Materials & $\mathbf{R}_{\mathbf{p}}(\mathbf{\Omega})$ & $\mathbf{R}_{\mathbf{c t}}(\mathbf{\Omega})$ \\
\hline N-LDH/2D-Pt & 2.0 & 5.2 \\
A-LDH/2D-Pt & 4.4 & 8.3 \\
2D-Pt & 7.9 & 12.1 \\
20\% Pt-C & - & 83.6 \\
{$[$ LDH + 2D-Pt $]$} & 9.4 & 12.6 \\
$(1: 1)$ & &
\end{tabular}

Here, $R_{p}$ represents the porosity resistance of the electrode, and $R_{c t}$ represents the charge transfer resistance. ${ }^{12}$ 


\section{References:}

1. Xu, Y.; Hao, Y.; Zhang, G.; Lu, Z.; Han, S.; Li, Y.; Sun, X. Room-Temperature Synthetic NiFe Layered Double Hydroxide with Different Anions Intercalation as an Excellent Oxygen Evolution Catalyst. RSC Adv. 2015, 5, 55131-55135.

2. Kim, J. G.; Kumar, A.; Lee, S. J.; Kim, J.; Lee, D. G.; Kwon, T.; Cho, S. H.; Lee, I. S. Concave Silica Nanosphere with a Functionalized Open-Mouthed Cavity as Highly Active and Durable Catalytic Nanoreactor. Chem. Mater. 2017, 29, 7785-7793.

3. Jeon, K. W.; Zhang, L.; Choi, S.; Lee, I. S. Colloids of Holey $\mathrm{Gd}_{2} \mathrm{O}_{3}$ Nanosheets Converted from Exfoliated Gadolinium Hydroxide Layers. Small 2018, 14, 1802174.

4. Zhao, S.; Wang, Y.; Dong, J.; He, C. T.; Yin, H.; An, P.; Zhao, K.; Zhang, X.; Gao, C.; Zhang, L. Ultrathin Metal-Organic Framework Nanosheets for Electrocatalytic Oxygen Evolution. Nat. Energy 2016, 1, 1-10.

5. Lao, M.; Rui, K.; Zhao, G.; Cui, P.; Zheng, X.; Dou, S. X.; Sun, W. Platinum/Nickel Bicarbonate Heterostructures towards Accelerated Hydrogen Evolution under Alkaline Conditions. Angew. Chem. Int. Ed. 2019, 58, 5432-5437.

6. Bai, L.; Gao, L.; Conway, B. E. Problem of In Situ Real-Area Determination in Evaluation of Performance of Rough or Porous, Gas-Evolving Electrocatalysts. $J$. Chem. Soc. Faraday Trans. 1993, 89, 235-242.

7. Qin, Y.; Ji, X.; Jing, J.; Liu, H.; Wu, H.; Yang, W. Size Control over Spherical Silver Nanoparticles by Ascorbic Acid Reduction. Colloids Surf. A Physicochem. Eng. Asp. 2010, 372, 172-176.

8. Tu, Y.-J.; Njus, D.; Schlegel, H. B. A Theoretical Study of Ascorbic Acid Oxidation and $\mathrm{HOO} / \mathrm{O}_{2}{ }^{--}$Radical Scavenging. Org. Biomol. Chem. 2017, 15, 4417-4431.

9. Patel, R.; Park, J. T.; Patel, M.; Dash, J. K.; Gowd, E. B.; Karpoormath, R.; Mishra, A.; Kwak, J.; Kim, J. H. Transition-Metal-Based Layered Double Hydroxides Tailored for Energy Conversion and Storage. J. Mater. Chem. A 2018, 6, 12-29.

10. Zheng, X.; Cui, P.; Qian, Y.; Zhao, G.; Zheng, X.; Xu, X.; Cheng, Z.; Liu, Y.; Dou, S. X.; Sun, W. Multifunctional Active-Center-Transferable Platinum/Lithium Cobalt 
Oxide Heterostructured Electrocatalysts towards Superior Water Splitting. Angew. Chem. Int. Ed. 2020, DOI: 10.1002/anie.202005241.

11. Wu, H.; Zuoa, X.; Wang, S.-P.; Yin, J.-W.; Zhang, Y.-N.; Chen, J. Theoretical and Experimental Design of Pt- $\mathrm{Co}(\mathrm{OH})_{2}$ Electrocatalyst for Efficient HER Performance in Alkaline Solution. Prog. Nat. Sci.: Mater. Int. 2019, 29, 356-361.

12. Rui, K.; Zhao, G.; Lao, M.; Cui, P.; Zheng, X.; Zheng, X.; Zhu, J.; Huang, W.; Dou, S. X.; Sun, W. Direct Hybridization of Noble Metal Nanostructures on 2D Metal-Organic Framework Nanosheets to Catalyze Hydrogen Evolution. Nano Lett. 2019, 19, 84478453. 